\title{
Raw and Sous-Vide-Cooked Red Cardoon Stalks (Cynara cardunculus L. var. altilis DC): (Poly)phenol Bioaccessibility, Anti-inflammatory Activity in the Gastrointestinal Tract, and Prebiotic Activity
}

\author{
Estíbaliz Huarte, Gessica Serra, Andrea Monteagudo-Mera, Jeremy Spencer, Concepción Cid, \\ and María-Paz de Peña*
}

Cite This: J. Agric. Food Chem. 2021, 69, 9270-9286

Read Online

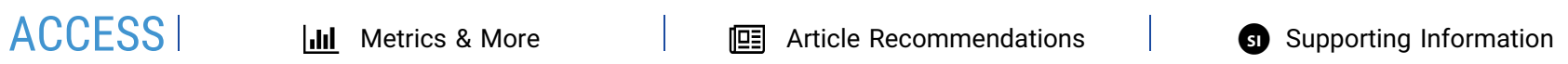

ABSTRACT: The in vitro anti-inflammatory and prebiotic activity and the content and profile of bioaccessible (poly)phenols and catabolites of raw and sous-vide-cooked red cardoon (Cynara cardunculus L. var. altilis DC) were investigated during gastrointestinal (GI) digestion. Raw cardoon after in vitro GI digestion had $0.7 \%$ bioaccessible (poly)phenols, which protected against lipopolysaccharide-induced inflammation by counteracting IL-8, IL-6, TNF- $\alpha$, and IL-10 secretions in differentiated Caco- 2 cells. Contrarily, GI-digested sous vide cardoon showed higher (poly)phenol bioaccessibility (59.8\%) and exerted proinflammatory effects in Caco-2 cells. (Poly)phenols were highly metabolized during the first $8 \mathrm{~h}$ of in vitro fermentation, and nine catabolites were produced during $48 \mathrm{~h}$ of fermentation. Colonic-fermented raw and sous-vide-cooked cardoon did not show anti-inflammatory activity in HT-29 cells but presented potential prebiotic activity, comparable to the commercial prebiotic FOS, by stimulating healthpromoting bacteria such as Bifidobacterium spp. and Lactobacillus/Enterococcus spp. and by increasing the production of total SCFAs, especially acetate.

KEYWORDS: Cynara, heat treatment, gastrointestinal digestion, (poly)phenols, cytokines, gut microbiota

\section{INTRODUCTION}

Diets consisting of low amounts of fruits, vegetables, and other fiber- and prebiotic-rich foods and high amounts of refined grains, alcohol, and ultra-processed foods are associated with changes in the gut microbiota composition and function (namely, dysbiosis) and lead to systemic chronic inflammation (SCI). ${ }^{1}$ In addition, there is evidence that SCI is implicated in disease onset or progression of metabolic syndrome. ${ }^{1}$ Therefore, it is of great importance to find nutritional or therapeutic interventions that help prevent or reduce an inflammatory state and maintain healthy microbiota.

Cultivated cardoon (Cynara cardunculus L. var. altilis DC), a Mediterranean plant belonging to the family Asteraceae, is mainly cultivated in Spain, Italy, Greece, France, and south Portugal. Cardoon stalks are usually consumed raw in salads or in a boiled form. Although the white variety is better known, stalks from the red cardoon variety are a richer source of (poly)phenols than those of the white variety. ${ }^{2}$ In addition, the application of heat treatments, such as frying and griddling, on cardoon stalks exerts a positive effect on the bioaccessibility of (poly)phenols, resulting in higher (poly)phenol bioaccessibility in digested cooked cardoons than in the raw ones after gastrointestinal (GI) digestion. ${ }^{3}$ Furthermore, the innovative culinary technique of sous vide cooking promoted a greater amount of caffeoylquinic acids (CQAs) both before and after GI digestion than traditional boiling in other Cynara vegetablelike globe artichoke. ${ }^{4}$

About $90 \%$ of dietary (poly)phenols, along with nondigestible carbohydrates and other plant components (such as lignin, resistant proteins, and carotenoids), are resistant to digestion and absorption in the small intestine. ${ }^{5}$ Thus, they reach the colon where they can be completely or partially hydrolyzed into smaller and more absorbable compounds by the gut microbiota. In a previous study on white cardoon stalks, gut microbiota action induced the formation of a higher total amount of the (poly)phenol-derived catabolites [protocatechuic acid, dihydrocaffeoylquinic, dihydrocaffeic, and 3-(3hydroxyphenyl)propionic acids] in fried and griddled cardoon stalks than in raw ones during an in vitro-simulated colonic fermentation. ${ }^{3}$ Thus, different bioaccesibilities of bioactive compounds and their catabolites between raw and cooked vegetables could impact their potential biological activity in the GI tract.

There is growing evidence of the ability of (poly)phenols to modulate inflammation, the gut microbiota composition, and metabolic activity. ${ }^{6-10}$ Then, throughout the upper and lower GI digestion processes, red cardoon bioactive compounds, such as (poly)phenols, and/or their resulting catabolites, might exert anti-inflammatory and/or prebiotic activity on the small intestine and/or the colon, before being absorbed into the blood or excreted. To the best of the authors' knowledge, there

Received: May 20, 2021

Revised: July 20, 2021

Accepted: July 26, 2021

Published: August 4, 2021

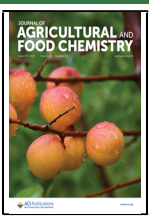


are no previous studies that evaluate the biological properties of red cardoon and neither the impact of culinary treatments and the GI digestion on its potential bioactivity. Therefore, this study aimed to investigate raw and sous-vide-cooked red cardoon stalks at different stages of in vitro upper and lower digestions (simulated oral-GI digestion and colonic fermentation) in terms of their (1) (poly)phenol bioaccessibility and metabolization by gut microbiota; (2) anti-inflammatory activity in the small intestine (differentiated Caco- 2 cells) or colon (HT-29 cells); and (3) potential prebiotic activity on fecal human microbiota.

\section{MATERIALS AND METHODS}

Chemicals and Reagents. Two plants of red cardoon stalks (C. cardunculus L. var. altilis DC) of approx. $50 \mathrm{~cm}$ in height and around $2.5 \mathrm{~kg}$ each, and harvested the day before, were purchased in a local retail store during the winter season (January 2019). Peptone water, yeast extract, bile salts, and phosphate buffered saline (PBS) tablets were obtained from Oxoid Ltd (Basingstoke, UK). Methanol, acetonitrile and $98 \%$ formic acid were acquired from PanReac AppliChem (Darmstadt, Germany). Pure phenolic standards were purchased from Sigma-Aldrich (Steinheim, Germany), except for dihydrocaffeic acid (Alfa Aesar, Thermo Fisher Scientific, Massachusetts, USA), the dicaffeoylquinic acids (diCQAs) 1,4-diCQA and 4,5diCQA (MedChem Express, New Jersey, USA), and 3,5-diCQA and apigenin (Extrasynthese, Genay, France). Low glucose (1 g/L) Dulbecco's modified Eagle's medium (DMEM) GlutaMAX containing pyruvate with and without phenol red; high glucose $(4.5 \mathrm{~g} / \mathrm{L})$ DMEM with and without phenol red; Dulbecco's PBS; $0.25 \%$ trypsin-ethylenediaminetetraacetic acid $(1 \times)$; penicillin-streptomycin; heat-inactivated fetal bovine serum (FBS); and MEM nonessential amino acids (100X) were obtained from Gibco (Paisley, UK). The standard fructooligosaccharide (FOS) OraftiP95 was purchased from BENEO-Orafti (Oreye, Belgium). Digestive enzymes, lipopolysaccharide (LPS) from Escherichia coli 026:B6, 3-(4,5dimethylthiazol-2-yl)-2,5-diphenyltetrazolium bromide (MTT), oligonucleotide probes, and other chemicals and reagents used were purchased from Sigma Aldrich (Poole, UK).

Red Cardoon Sample Preparation. Cardoon stalks were washed, and the spiny skin was removed manually. Then, they were cut into rectangular homogeneous pieces $(1.5 \times 6 \mathrm{~cm}$ approx. $)$, manually mixed together, and divided into two parts $(1.8 \mathrm{~kg}$ each). One-half was named raw cardoon and lyophilized in a freeze dryer Cryodos-80 (Telstar, Terrasa, Spain). The other half was packaged into a total of 33 vacuum bags, each one containing around $55 \mathrm{~g}$ of fresh cardoon stalks and a thin layer of water $(45 \mathrm{~mL})$. The bags were then vacuum-sealed by using a vacuum sealer (VP-3710.10 AKRamon, Vilassar de Dalt, Barcelona, Spain), immersed in boiling water $\left(98^{\circ} \mathrm{C}\right)$, and then maintained at $85^{\circ} \mathrm{C}$ for $50 \mathrm{~min}$. Water temperature was controlled with a temperature probe. All sous-vide-cooked cardoon stalks were lyophilized in a freeze dryer Cryodos- 80 (Telstar, Terrasa, Spain), then crushed with a chopper (Moulinex, Barcelona, Spain), and pooled to have a representative sample of sous-videcooked cardoon, avoiding thermal process variability. Lyophilized raw and sous-vide-cooked cardoon samples were stored at $-18^{\circ} \mathrm{C}$ until analysis.

Simulated Oral-GI Digestion. Red cardoon samples underwent an oral-GI in vitro digestion according to the method described by Mills et al. ${ }^{11}$ with some modifications. Briefly, $350 \mathrm{~mL}$ of distilled water were added to $35 \mathrm{~g}$ of each freeze-dried sample in a glass screw topped bottle placed in a room at $37^{\circ} \mathrm{C}$. The bottle was shaken and connected to a $\mathrm{pH}$ sensor. Three sequential steps were performed in the absence of light. First, the oral digestion was performed by adding $3.65 \mathrm{~mL}$ of the $\alpha$-amylase solution from Bacillus licheniformis (47.9 U/ $\mathrm{mL}$ ) to each bottle and then, the sample was shaken for $30 \mathrm{~min}$. Second, the gastric digestion step was carried out by adding $14.6 \mathrm{~mL}$ of a porcine pepsin solution $(589.2 \mathrm{U} / \mathrm{mL})$, and distilled water up to $650 \mathrm{~mL}$. Samples were shaken for $2 \mathrm{~h}$ maintaining $\mathrm{pH} 3$ by adding 6
$\mathrm{M} \mathrm{HCl}$. Finally, the intestinal step was accomplished by adding 72.9 $\mathrm{mL}$ of a porcine pancreatin solution (33 $\mathrm{U}$ trypsin/mL) with bile extracts $(2.76 \mathrm{mg} / \mathrm{mL})$. Samples were shaken for $2 \mathrm{~h}$ at $\mathrm{pH} 7$ by the addition of $6 \mathrm{M} \mathrm{NaOH}$. The enzymatic digestive extract of each cardoon sample was divided into 3 fractions. The first fraction (300 $\mathrm{mL}$ ) was freeze-dried (ScanVac CoolSafe, Labogene, Lillerød, Denmark) and stored at $-80{ }^{\circ} \mathrm{C}$ until (poly)phenol analysis, and the second fraction $(150 \mathrm{~mL}$ ) was used for analysis of cytotoxicity and impact on cytokine secretion in differentiated Caco- 2 cells. The third fraction $(220 \mathrm{~mL})$ was transferred into a cellulose dialysis membrane (100-500 Da molecular weight cutoff, $1.8 \mathrm{~mL} / \mathrm{cm}, 24 \mathrm{~mm}, 100 \mathrm{M}$ Spectra/Por Liotech) (Fisher Scientific, Loughborough, UK) and dialyzed overnight at $4{ }^{\circ} \mathrm{C}$ against $0.01 \mathrm{M} \mathrm{NaCl}(4 \mathrm{~L})$ to remove lowmolecular-weight digestion products and monosaccharides. The dialysis fluid was changed and dialysis continued for an additional 2 h. The digest retained in the dialysis tube represent the nonabsorbed sample in the small intestine that might pass to the colon and be fermented by gut microbiota. This retained digest was freeze-dried (ScanVac CoolSafe, Labogene, Lillerød, Denmark) and stored at -18 ${ }^{\circ} \mathrm{C}$ until fermentation, or at $-80{ }^{\circ} \mathrm{C}$ until (poly)phenol analysis.

Fecal Sample Preparation. Human fecal samples from three healthy volunteers were collected on the day of the inoculation of the batch culture vessels in anaerobic jars (Anaerojar TM 2.5L, Oxoid Ltd), which included a gas-generating kit (AnaeroGen TM, Oxoid). They were processed within $1 \mathrm{~h}$ of bowel movement. All the volunteers had not taken any antibiotics for at least 6 months before the study and had no history of bowel or GI disease and followed a polyphenol-free diet (avoiding fruits and vegetables, nuts, legumes, high-fiber products, and beverages such as tea, coffee, and fruit juices, as well as alcohol) for 2 days before fecal collection. Fecal slurry from each individual was prepared by homogenizing human feces $(10 \% \mathrm{w} /$ v) in PBS (0.1 M; pH 7.4) in a stomacher (Stomacher 400, Seward, Norfolk, UK) at 460 paddle beats/min for $2 \mathrm{~min}$.

Simulated Colonic Fermentation. GI-digested and dialyzed cardoon samples were submitted to an in vitro-simulated colonic fermentation using fecal batch cultures. In order to mimic conditions located in the distal region of the human large intestine, the experiment was run under anaerobic conditions at $37^{\circ} \mathrm{C}$ and $\mathrm{pH} 6.7-$ 6.9 for a period of $48 \mathrm{~h}$. Briefly, sterilized glass water-jacketed vessels $(300 \mathrm{~mL})$ were aseptically filled with a presterilized basal nutrient medium $(135 \mathrm{~mL})$ containing the following: peptone water $(2 \mathrm{~g} / \mathrm{L})$, yeast extract $(2 \mathrm{~g} / \mathrm{L}), \mathrm{NaCl}(0.1 \mathrm{~g} / \mathrm{L}), \mathrm{K}_{2} \mathrm{HPO}_{4}(0.04 \mathrm{~g} / \mathrm{L}), \mathrm{KH}_{2} \mathrm{PO}_{4}$ $(0.04 \mathrm{~g} / \mathrm{L}), \mathrm{MgSO}_{4} \cdot 7 \mathrm{H}_{2} \mathrm{O}(0.01 \mathrm{~g} / \mathrm{L}), \mathrm{CaCl}_{2} \cdot 6 \mathrm{H}_{2} \mathrm{O}(0.01 \mathrm{~g} / \mathrm{L})$, $\mathrm{NaHCO}_{3}(2 \mathrm{~g} / \mathrm{L})$, Tween $80(2 \mathrm{~mL} / \mathrm{L})$, hemin $(0.05 \mathrm{~g} / \mathrm{L})$, vitamin $\mathrm{K} 1(10 \mathrm{~mL} / \mathrm{L})$, L-cysteine $(0.5 \mathrm{~g} / \mathrm{L})$, bile salts $(0.5 \mathrm{~g} / \mathrm{L})$, resazurin $(1$ $\mathrm{mg} / \mathrm{L}$ ), and distilled water. The vessels were then gassed overnight with $\mathrm{O}_{2}$-free $\mathrm{N}_{2}(15 \mathrm{~mL} / \mathrm{min})$ and magnetically stirred. The following day, the temperature of the vessels was set to $37{ }^{\circ} \mathrm{C}$ by use of a circulating water bath, and the $\mathrm{pH}$ was maintained at 6.7-6.9 using an Electrolab pH controller (Tewksbury, UK). Then, $1.5 \mathrm{~g}$ of each freeze-dried digested sample $(1 \% \mathrm{w} / \mathrm{v}$ final volume) was added to the stirred vessels just before the addition of $15 \mathrm{~mL}$ of the fecal slurry (1\% $\mathrm{w} / \mathrm{v}$ final volume). The prebiotic FOS OraftiP95 at $1 \% \mathrm{w} / \mathrm{v}$ final volume was included as the positive fermentation control, and basal nutrient media with no substrate was added as the negative fermentation control (NFC). Batch cultures were run for $48 \mathrm{~h}$ and were performed in triplicate with three different fecal volunteers for each substrate. Aliquots from cardoon sample and control fermentation were collected at various time points for (poly)phenol and catabolite analysis $(15 \mathrm{~mL}$ at $0,4,8,24$, and $48 \mathrm{~h}$ ), cytotoxicity and impact on cytokine secretion analysis in HT-29 cells $(5 \mathrm{~mL}$ at 8 and $24 \mathrm{~h}$ ), and bacterial enumeration and lactic acid and short-chain fatty acid (SCFA) analysis (5 mL at $0,8,24$ and $48 \mathrm{~h}$ ). Collected aliquots for the analysis of (poly)phenols and catabolites were immediately inactivated with $50 \mu \mathrm{L}$ of $33 \% \mathrm{HCl}$, then freeze-dried (Cryodos-80, Telstar, Terrasa, Spain), and stored at $-80^{\circ} \mathrm{C}$.

Analysis of (Poly)phenols and Catabolites by HighPerformance Liquid Chromatography with Tandem Mass Spectrometry. (Poly)phenols and catabolites were extracted from the undigested, digested (with and without subsequent dialysis), and 
fermented cardoon samples, following the Sánchez-Salcedo et al. procedure $^{12}$ with some modifications. Briefly, $25 \mathrm{mg}$ of each freezedried sample were extracted with $0.5 \mathrm{~mL}$ of $80: 20(\mathrm{v} / \mathrm{v})$ methanol/ acidified water ( $0.1 \%$ formic acid) and sonicated for $90 \mathrm{~min}$. Afterward, the mixture was centrifuged for $10 \mathrm{~min}$ at $19,956 \mathrm{~g}$. The supernatant was collected and the residue was re-extracted using 0.25 $\mathrm{mL}$ of $80: 20 \mathrm{v} / \mathrm{v}$ methanol/acidified water, sonicated for $25 \mathrm{~min}$ in a sonic bath, and centrifuged for $10 \mathrm{~min}$ at $19,956 \mathrm{~g}$. Both supernatants were mixed, filtered with a $0.22 \mu \mathrm{m}$ PVDF syringe filter, and stored at $-18{ }^{\circ} \mathrm{C}$ until high-performance liquid chromatography with tandem mass spectrometry (HPLC-MS/MS) analysis.

(Poly)phenols and catabolites in the extracts were analyzed using an HPLC unit model 1200 (Agilent Technologies, Palo Alto, CA, USA) equipped with a triple quadrupole linear ion-trap mass spectrometer (3200 Q-TRAP, AB SCIEX). The column used was a CORTECS C18 $(3 \times 75 \mathrm{~mm}, 2.7 \mu \mathrm{m})$ from Waters. The HPLC separation was carried out using $0.1 \% \mathrm{v} / \mathrm{v}$ formic acid in water (solvent A) and acetonitrile (solvent B) at a constant flow rate of 0.6 $\mathrm{mL} / \mathrm{min}$ and a column oven temperature of $20{ }^{\circ} \mathrm{C}$. The injection volume was $5 \mu \mathrm{L}$. The mobile phase program was established as follows: $0-1 \mathrm{~min}, 5 \% \mathrm{~B} ; 1-5 \min , 5-10 \% \mathrm{~B}$; 5-8 min, $10-20 \% \mathrm{~B}$; $8-10.5 \mathrm{~min}, 20 \% \mathrm{~B} ; 10.5-16 \mathrm{~min}, 20-30 \% \mathrm{~B} ; 16-17.6 \mathrm{~min}, 30-$ $100 \% \mathrm{~B} ; 17.6-25.6 \mathrm{~min}, 100 \% \mathrm{~B}$, then returned to $5 \% \mathrm{~B}$ in $4.8 \mathrm{~min}$ and maintained an isocratic elution until the end of the analysis (35 $\min$ ). For the identification and quantification of (poly)phenols and catabolites, the ion multiple reaction monitoring mode was used. The MS worked in the negative ionization mode, with a source temperature of $600{ }^{\circ} \mathrm{C}$ and the IonSpray voltage of $-3500 \mathrm{~V}$. Nitrogen was used as nebulizing, turbo heater, and curtain gas and it was set at the pressures of $-60,-65$, and -35 psi, respectively. The declustering and entrance potentials were set at -20 and $-10 \mathrm{~V}$, respectively. The collision energy was optimized for each compound using the same standards as those used for identification. Compounds were identified by comparing the MS/MS fragmentation pattern and retention time with pure reference standards when available. When no standard was available, compounds were tentatively identified by comparing the MS/MS fragmentation with the literature fragmentation pathway. The retention time and mass spectrometric characteristics of (poly)phenols and catabolites identified as well as the pure reference standards used are shown in Table S1.

(Poly)phenols and catabolites were quantified by using the calibration curves of their own pure reference standard when available. For those compounds without a pure reference standard, 1-CQA and CQA derivatives I-III were quantified as 5-CQA equivalents; diCQA glucosides I-II and succinyldiCQAs I-II as 4,5diCQA equivalents; caffeoyl-hexoside was quantified as isoquercitrin equivalents; and luteolin acetylglucoside was quantified as luteolin 7$\mathrm{O}$-glucoside equivalents. The limit of quantification (LOQ) was 0.25 $\mu \mathrm{g} / \mathrm{mL}$ for hesperidin and phenylacetic acid; $0.05 \mu \mathrm{g} / \mathrm{mL}$ for $1,3-$ diCQA, isoferulic acid, quercetin, 3-hydroxyphenylacetic acid, protocatechuic acid, and 4-hydroxybenzoic acid; and $0.025 \mu \mathrm{g} / \mathrm{mL}$ for the rest of the standards used. Chromatograms and spectral data were acquired using Analyst software 1.6.3 (AB SCIEX). Those polyphenols or catabolites detected and quantified in the NFC samples were subtracted from the colonic fermented cardoon samples. Each sample was analyzed in duplicate. The results are presented as the mean of micrograms of (poly)phenol per gram of the cardoon sample dry matter $(\mu \mathrm{g} / \mathrm{g} \mathrm{dm}) \pm$ standard deviation $(\mathrm{SD})$.

The bioaccessibility of (poly)phenols from digested (with and without subsequent dialysis) and fermented cardoon samples was determined as follows:

$$
\text { bioaccessibility }=\frac{\mathrm{TPC}_{\text {after }}}{\mathrm{TPC}_{\text {before }}} \times 100 \%
$$

where $\mathrm{TPC}_{\text {before }}$ is the total poly(phenol) content before digestion and $\mathrm{TPC}_{\text {after }}$ is the total poly(phenol) content after digestion/dialysis/ fermentation.

Cell Culture Conditions and Treatments. Caco- 2 cells (human colon adenocarcinoma cells) were purchased from the European
Collection of Cell Cultures (ECACC) (Salisbury, Wiltshire UK) and cultured in low glucose $(1 \mathrm{~g} / \mathrm{L})$ DMEM containing pyruvate and glutamine and supplemented with $1 \%(\mathrm{v} / \mathrm{v})$ of nonessential amino acids. HT-29 cells (human colon adenocarcinoma cell line) were obtained from ECACC and cultured in high glucose (4.5 g/L) DMEM containing L-glutamine. Cell media from both cell lines were supplemented with $10 \% \mathrm{v} / \mathrm{v}$ FBS, $100 \mathrm{U} / \mathrm{mL}$ penicillin, and $0.1 \mathrm{mg} /$ $\mathrm{mL}$ streptomycin. Cells were incubated in a humidified atmosphere at $5 \% \mathrm{CO}_{2}$ and $37^{\circ} \mathrm{C}$ and sub-cultured 2-3 times per week.

For experiments with Caco- 2 cells, fractions collected after the digestion of cardoon samples were immediately centrifuged at $1543.5 \mathrm{~g}$ for $15 \mathrm{~min}$, and the resulting supernatants were collected and $0.45 \mu \mathrm{M}$ filtered to separate the soluble fraction that might be available for absorption into intestinal cells (bio-accessible fraction). For experiments with HT-29 cells, aliquots collected during the fermentation of cardoon samples or from the NFC of the three volunteers at the same fermentation time $(8$ or $24 \mathrm{~h})$ were combined and centrifuged $(1543.5 \mathrm{~g}, 10 \mathrm{~min})$. Then, supernatants were 0.45 and $0.22 \mu \mathrm{M}$ filtered to obtain the potentially bio-accessible fraction for colon cells. The filtered supernatants of the digestion and fermentation of cardoon samples and the NFC were divided in small aliquots $(1.5 \mathrm{~mL})$ and stored at $-20{ }^{\circ} \mathrm{C}$ for use.

Cells were seeded in 96 -well plates $\left(3.4 \times 10^{4}\right.$ cells $/ \mathrm{mL}$ for Caco-2 cells and $2.2 \times 10^{5}$ cells $/ \mathrm{mL}$ for HT-29 cells; $150 \mu \mathrm{L} /$ well $)$ for the MTT assay and in 24-well plates $\left(3.12 \times 10^{4}\right.$ cells $/ \mathrm{mL}$ for Caco-2 cells and $1.84 \times 10^{5}$ cells $/ \mathrm{mL}$ for HT-29 cells; $1 \mathrm{~mL} /$ well) for the Luminex assay. Caco-2 cells were allowed to grow to confluent monolayers for 19 days at $37{ }^{\circ} \mathrm{C}$ and $5 \% \mathrm{CO}_{2}$ prior to the experiments in order to differentiate and develop an enterocyte-like phenotype. Their cell media were changed every 3 days. HT-29 cells were incubated for $24 \mathrm{~h}$ at $37{ }^{\circ} \mathrm{C}$ and $5 \% \mathrm{CO}_{2}$, reaching a sub-confluent state prior to the experiments.

Different LPS concentrations and exposure times $(0.1-50 \mu \mathrm{g} / \mathrm{mL}$, 24-72 h) were preliminarily analyzed in both cell lines, and in undifferentiated Caco-2 cells, for their cytotoxicity (MTT assay) and impact on cytokine secretion (Luminex multiplex assay). Undifferentiated Caco-2 cells were dismissed due to their undetectable [interleukin (IL)-1 $\beta, \mathrm{IL}-6, \mathrm{IL}-10$, and tumor necrosis factor (TNF)- $\alpha$ ] or very low (IL-8) capacity to secrete cytokines in response to LPS. LPS at 5 and $0.1 \mu \mathrm{g} / \mathrm{mL}$ in the differentiated Caco-2 and HT-29 cells, respectively, and $48 \mathrm{~h}$ of exposure were selected as the treatment to induce an inflammatory state in cells on the basis of its ability to stimulate high cytokine secretion without being cytotoxic. Furthermore, the cytotoxicity of supernatants of cardoon sample digestion $(2.5-20 \% \mathrm{v} / \mathrm{v}$ in cell media, which corresponds to $1.21-9.68 \mathrm{mg} \mathrm{dm} /$ $\mathrm{mL})$ or fermentation $(0.1-10 \% \mathrm{v} / \mathrm{v}$ in cell media, which corresponds to $9.53-953.2 \mu \mathrm{g} \mathrm{dm} / \mathrm{mL}$ ) was previously analyzed by the MTT assay in both cell lines. Then, noncytotoxic concentrations were selected for the assessment of the anti-inflammatory potential, which were 2.42 and $9.68 \mathrm{mg}$ cardoon $\mathrm{dm} / \mathrm{mL}$ for the digested cardoon samples ( $\geq 88 \%$ MTT reduction relative to the control, both in the absence and in the presence of $5 \mu \mathrm{g} / \mathrm{mL}$ LPS) (Figure S1a) and 23.8 and 95.3 $\mu \mathrm{g}$ cardoon $\mathrm{dm} / \mathrm{mL}$ for fermented cardoon samples (>80\% MTT reduction relative to the control, both in the absence and in the presence of $5 \mu \mathrm{g} / \mathrm{mL}$ LPS) (Figure S1b).

Once the concentrations and exposure times were optimized, the experiments were carried out under the following conditions: on the day of the experiment, the cell medium was removed, and differentiated Caco-2 cells were washed with phenol red-free DMEM at $2.5 \%$ FBS and HT-29 cells with PBS. Differentiated Caco-2 cells were pretreated for $1 \mathrm{~h}$ with two selected supernatant concentrations of the GI-digested cardoon samples $(2.42$ and $9.68 \mathrm{mg}$ cardoon $\mathrm{dm} / \mathrm{mL}$ which are equivalent to 5 and $20 \% \mathrm{v} / \mathrm{v}$ in cell media, respectively). Besides, HT-29 cells were pretreated for $1 \mathrm{~h}$ with two selected supernatant concentrations of 8 and $24 \mathrm{~h}$ colonic-fermented cardoon samples (23.8 and $95.3 \mu \mathrm{g}$ cardoon $\mathrm{dm} / \mathrm{mL}$, which are equivalent to 0.25 and $1 \% \mathrm{v} / \mathrm{v}$ in cell media, respectively) and two supernatant concentrations of 8 and $24 \mathrm{~h} \mathrm{NFC}(0.25$ and $1 \% \mathrm{v} / \mathrm{v}$ in cell media). Treatments continued in both cell lines for a further $48 \mathrm{~h}$ in the absence and presence of LPS at 5 and $0.1 \mu \mathrm{g} / \mathrm{mL}$ for 
differentiated Caco-2 and HT-29 cells, respectively. Blank controls were introduced in the experiments with both differentiated Caco-2 cells and HT-29 cells consisting of cells incubated with phenol redfree cell media at $2.5 \%$ FBS.

Cytokine Quantification by the Luminex Multiplex Assay. After the aforementioned treatments (see section "Cell Culture Conditions and Treatment"), well contents were removed, transferred to Eppendorf tubes, and stored at $-20{ }^{\circ} \mathrm{C}$. The day of the analysis, tubes were defrosted and centrifuged at $16,000 \mathrm{~g}$ for $5 \mathrm{~min}$ (Centrifuge Thermo Scientific, Heraeus Fresco 17, Massachusetts, United States). The concentration of IL- 8 , IL- 6 , IL- $1 \beta$, TNF- $\alpha$, and IL-10 on the diluted supernatants was measured using a bead-based Luminex multiplex assay (Human High Sensitivity Cytokine Premix Kit A, Magnetic Luminex High Performance Assay, R\&D Systems, United Kingdom) following the manufacturer's instructions. The analysis was carried out with a Luminex 200 System and Luminex Xponent software (Luminex Corporation, Austin, Texas, USA). Three independent experiments were performed.

Enumeration of Bacterial Populations by Fluorescence In Situ Hybridization. Aliquots $(750 \mu \mathrm{L})$ collected from the fermentation of the cardoon samples were immediately centrifuged for $5 \mathrm{~min}$ at $11,338 \mathrm{~g}$. The pellet was resuspended in $375 \mu \mathrm{L}$ of PBS and fixed in $1125 \mu \mathrm{L}$ of the $4 \% \mathrm{w} / \mathrm{v}$ paraformaldehyde solution at 4 ${ }^{\circ} \mathrm{C}$ for $4 \mathrm{~h}$. Fixed samples were centrifuged at $11,338 \mathrm{~g}$ for $5 \mathrm{~min}$, and the cell pellet was washed twice in $1 \mathrm{~mL}$ of sterile cold PBS $(0.1 \mathrm{M}$, $\mathrm{pH} 7.0)$ and centrifuged at $11,338 \mathrm{~g}$ for $5 \mathrm{~min}$. Finally, the cell pellet was resuspended in PBS $(300 \mu \mathrm{L})$ and $99 \%$ ethanol $(300 \mu \mathrm{L})$ and stored at $-20{ }^{\circ} \mathrm{C}$ until analysis. Then, bacterial populations were enumerated by fluorescence in situ hybridization (FISH) using oligonucleotide probes targeting specific regions of $16 \mathrm{~S}$ rRNA. Probes were commercially synthesized and labeled with the fluorescent dye Cy3. The following probes were used: Bif164 for Bifidobacterium spp.; ${ }^{13}$ Lab158 for Lactobacillus/Enterococcus; ${ }^{14}$ Erec482 for Eubacterium rectale-Clostridium coccoides group (Clostridium cluster XIVa); ${ }^{15}$ Bac303 for Bacteroides-Prevotella group; ${ }^{16}$ and EUB 338 mixture consisting of EUB338, EUB338II, and EUB338III for total bacteria. ${ }^{17}$ Fixed samples were hybridized as described by Daims, Stoecker, and Wagner. ${ }^{18}$ Bacterial cells were counted in 15 random fields of view per sample using a fluorescence microscope (Nikon E400 Eclipse, Tokyo, Japan). Three independent fermentation aliquots of cardoon samples with fecal samples from 3 different donors were analyzed.

Analysis of Lactic Acid and SCFAs by Gas Chromatography with Flame Ionization Detection. Aliquots $(1 \mathrm{~mL})$ collected from the fermentation of cardoon samples were immediately centrifuged $(11,338 \mathrm{~g}$ for $10 \mathrm{~min})$ to remove bacteria and other solids. Supernatants were then transferred into clean tubes and frozen at $-20{ }^{\circ} \mathrm{C}$. Then, lactic acid and SCFAs from the fermented samples were extracted and derivatized as previously described. ${ }^{19}$ Briefly, 500 $\mu \mathrm{L}$ of each sample or standard solution were added to a $100 \mathrm{~mm} \times 16$ mm flat-bottomed glass tube with $25 \mu \mathrm{L}$ of $0.1 \mathrm{M}$ 2-ethylbutyric acid as the internal standard. Then, $250 \mu \mathrm{L}$ of the concentrated $\mathrm{HCl}$ and $1.5 \mathrm{~mL}$ of diethyl ether were added to each tube, vortexed for $1 \mathrm{~min}$, and centrifuged $(10 \mathrm{~min}$ at $752 \mathrm{~g})$. Tubes were left at room temperature overnight and the day after, $500 \mu \mathrm{L}$ of diethyl ether (the upper layer) were transferred into GC screw-cap vials. Then, 25 $\mu \mathrm{L}$ of $N$-(tert-butyldimethylsilyl)- $N$-methyltrifluoroacetamide was added to each vial with the ether extract. Then, the vials were left at room temperature for $72 \mathrm{~h}$ to allow lactic acid in the samples to completely derivatize. Then, a 7890B Gas Chromatograph (Agilent Technologies, Cheshire, UK) equipped with FID was used for the analysis of lactic acid and SCFAs in the fermented samples. The column used was a HP-5MS $(30 \mathrm{~m} \times 0.25 \mathrm{~mm} \times 0.25 \mu \mathrm{m}$; HP-5 $5 \%$ diphenyl/95\% dimethylpolysiloxane) from Agilent Technologies. Both the injector and detector were held at $275{ }^{\circ} \mathrm{C}$. The sample injection volume was $1 \mu \mathrm{L}$, and a split ratio of $100: 1$ was used. The carrier gas helium was set at 5 psi and a flow rate of $6.5 \mathrm{~mL} / \mathrm{min}$. The GC oven was held at $63{ }^{\circ} \mathrm{C}$ for $3 \mathrm{~min}$, programed to $190{ }^{\circ} \mathrm{C}$ at $10^{\circ} \mathrm{C} /$ min, and then held constant at $190{ }^{\circ} \mathrm{C}$ for $1 \mathrm{~min}$. Lactic acid and SCFAs (acetic, propionic, butyric, isobutyric, and isovaleric acids) were quantified by using a calibration curve performed with a standard solution at concentrations of $6.25-50 \mathrm{mM}$. Peak areas were integrated and calculated using ChemStation B.01.04.232 software (Agilent Technologies, Cheshire, UK). Three independent fermentation aliquots of cardoon samples with fecal samples from three different donors were analyzed.

Statistical Analysis. One-way analysis of variance (ANOVA) with Tukey's post hoc test was conducted to determine the differences in cytokine concentrations between each treatment and control (untreated cells and NFC-treated cells; with or without LPS stimulation), as well as differences among the raw and cooked cardoon treatments at the same concentration. ANOVA and Tukey's post hoc test was also applied to determine the significant differences in bacterial counts, and in lactic acid and SCFA concentrations, among treatments (NFC, FOS, raw, and sous-vide-cooked cardoon) at the same fermentation time points $(0,8,24$, and $48 \mathrm{~h})$. Differences in bacterial counts, and in lactic acid and SCFA concentrations, from $0 \mathrm{~h}$ of fermentation value within the same treatment were tested using the paired Student's $t$ test. Differences were considered significant if $p$ value $<0.05$. All the statistical analyses were performed using the STATA v.12.0 software package.

\section{RESULTS}

(Poly)phenol and Catabolite Bioaccessibility during GI-Digestion and Colonic Fermentation. A total of 19 and 30 (poly)phenols were identified and quantified in raw and sous-vide-cooked red cardoon (nondigested), respectively (Tables 1 and 2). Phenolic acids, and specifically hydroxycinnamic acids, represented $>98 \%$ of the total content in both samples, with mono- and di-CQAs as the major (poly)phenolic compounds (43.4-48.7 and 55.5-49.2\% of total polyphenols, respectively). The remaining (poly)phenols were flavonoids (apigenin, luteolin, quercetin, and hesperetin derivatives), being luteolin derivatives (luteolin 7-O-glucoside, luteolin 7-Oglucuronide, and luteolin acetylglucoside) the most abundant ones.

Despite raw and sous-vide-cooked red cardoon having a similar total content of (poly)phenols (13.15 and $13.14 \mathrm{mg} / \mathrm{g}$ $\mathrm{dm}$ respectively), differences in the content or in the individual (poly)phenol profile were found. The most abundant (poly)phenols were 5-CQA (29.3-41.8\% of total polyphenols) and 1,5-diCQA $(20.7-39.2 \%$ of total polyphenols) in both cardoon samples, along with 3,5-diCQA (13.0\% of total polyphenols) in raw cardoon, and 1,3-diCQA (18.2\%) in the sous vide one. In addition, undigested raw cardoon showed a higher content of 5-CQA (1.4-fold), 1,5-diCQA (3-fold), 3,5diCQA (1.9-fold), and succinyldiCQA I (2-fold) and II (13.7fold) than sous vide cardoon. On the contrary, 11 (poly)phenols (i.e., CQA derivatives I-III, 3,4-diCQA, diCQA glucoside I, ferulic and isoferulic acids, apigenin, vicenin-2, luteolin, and hesperedin), which were only found in trace amounts or not detected in the raw cardoon, could be quantified in the sous vide one.

After an in vitro simulated oral-GI digestion, the content of individual (poly)phenols substantially decreased in both samples (Table 1 ), reaching a bioaccessibility of $0.7 \%$ (or $0.5 \%$ after dialysis) in digested raw cardoon, whereas $59.8 \%$ (or $38.1 \%$ after dialysis) of (poly)phenols still remained bioaccessible in digested sous-vide-cooked cardoon (Table 2).

During the $48 \mathrm{~h}$ in vitro simulated colonic fermentation, (poly)phenol bioaccessibility of raw and sous vide cardoon gradually decreased, while 9 catabolites were detected at different fermentation time points (Table 1). In addition, flavonoid aglycones such as luteolin and apigenin, as well as low-molecular-weight hydroxycinnamic acids, such as caffeic acid, increased during $4-8 \mathrm{~h}$ of fermentation but decreased 


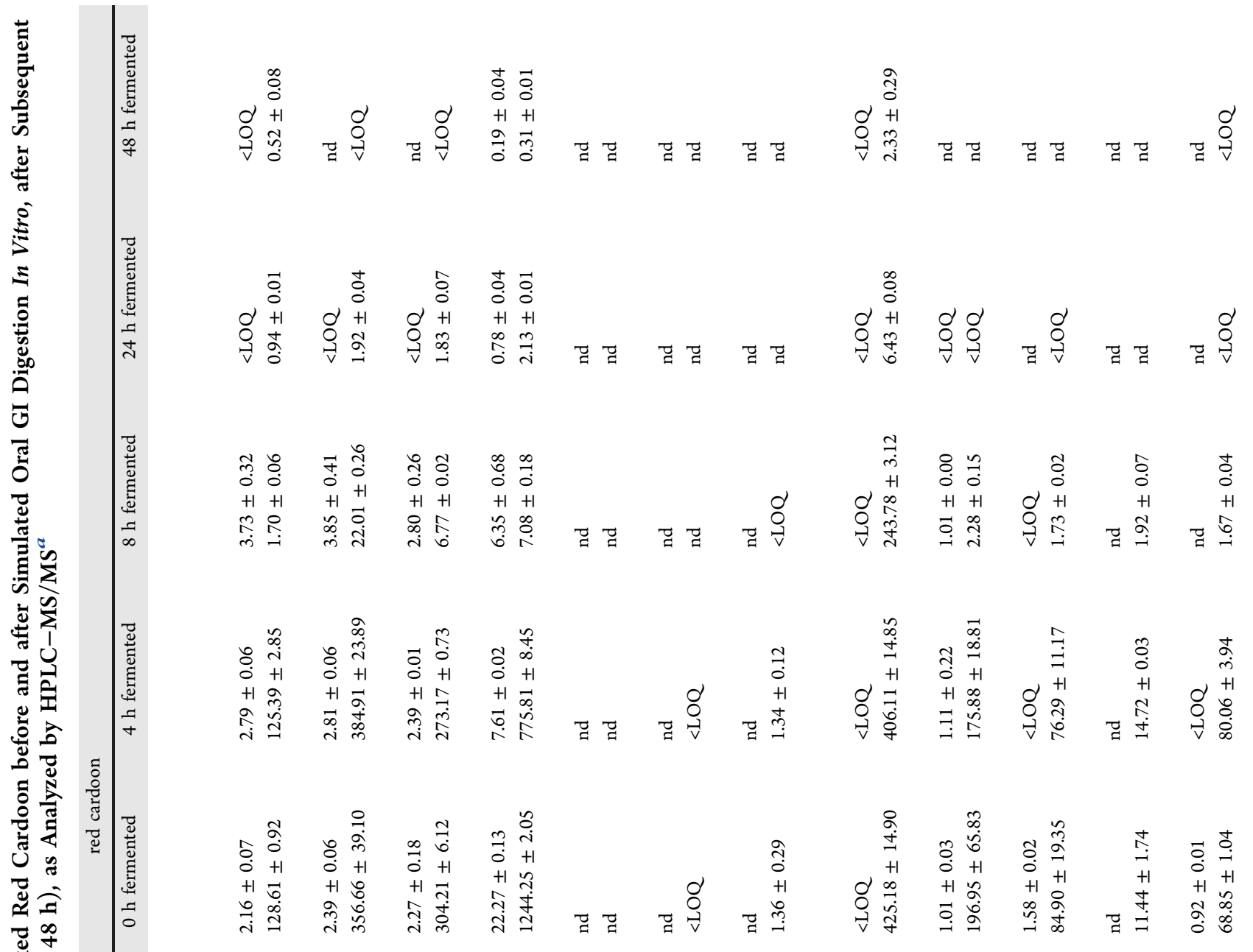

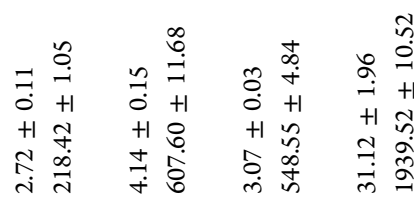

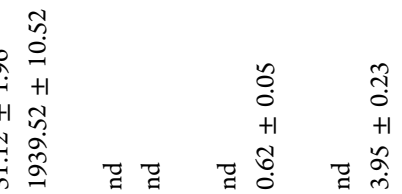

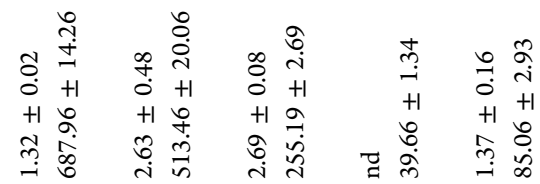

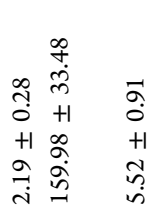

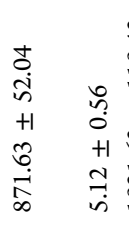

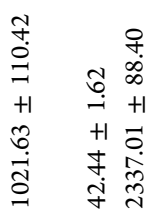

0
+
$\infty$
$\infty$
+1
0
0
$\stackrel{0}{3}$
$\stackrel{N}{N}$

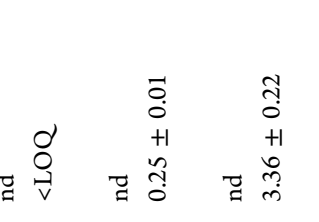

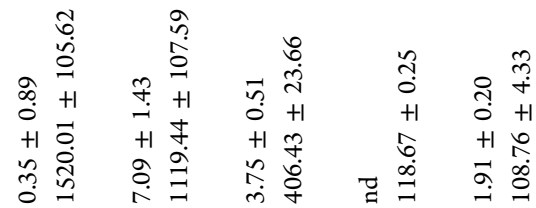

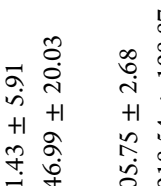

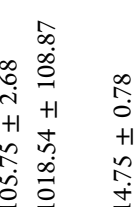

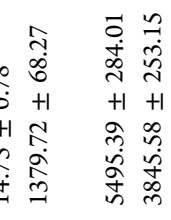

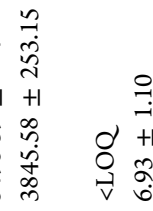

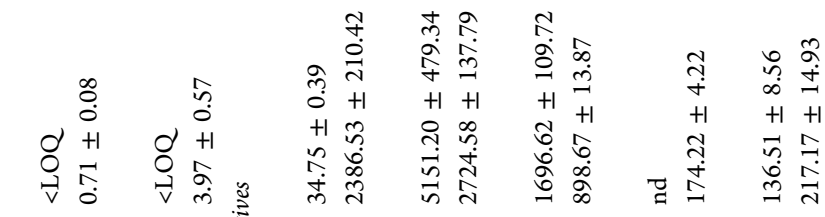




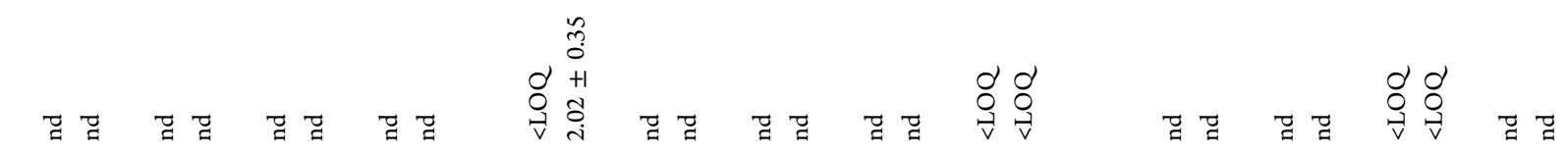

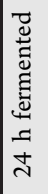

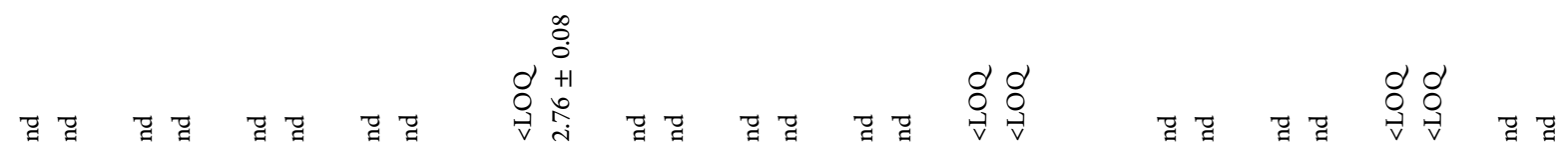

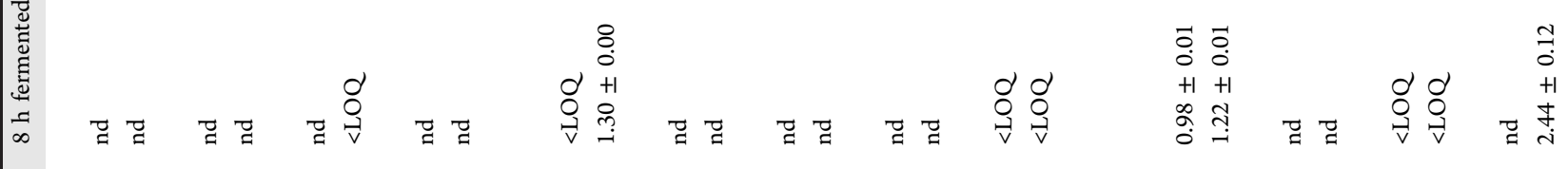

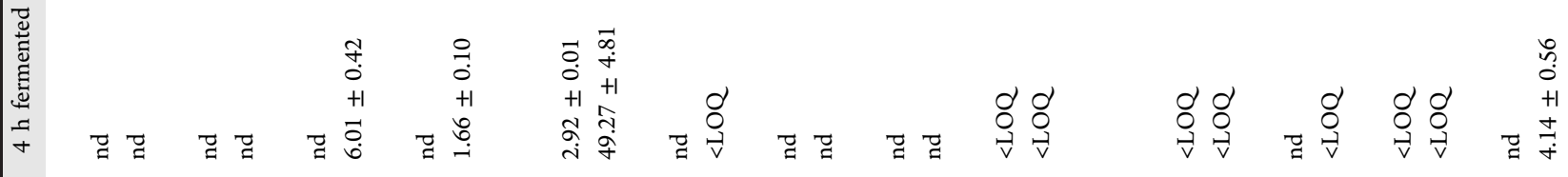

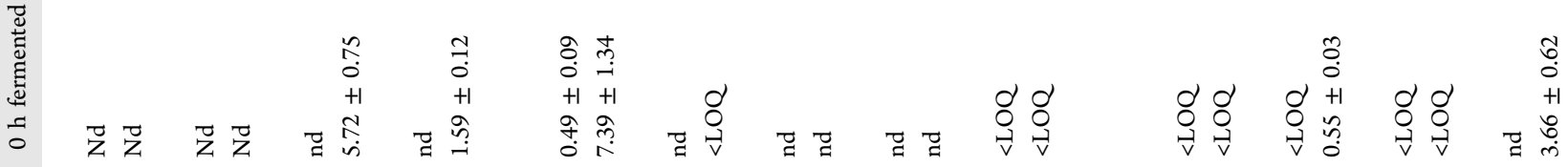

苋

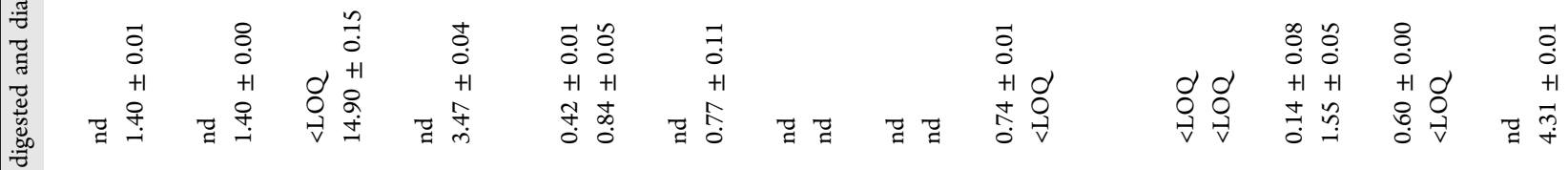

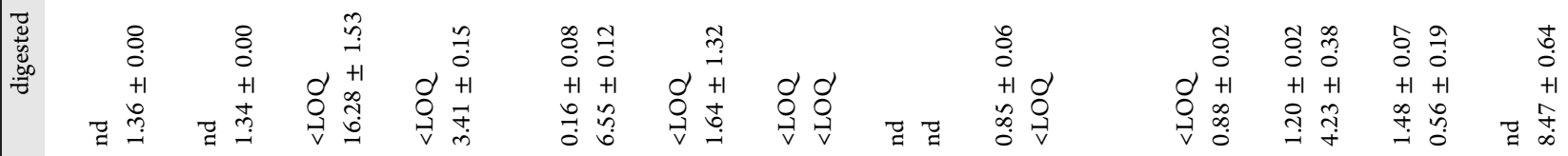

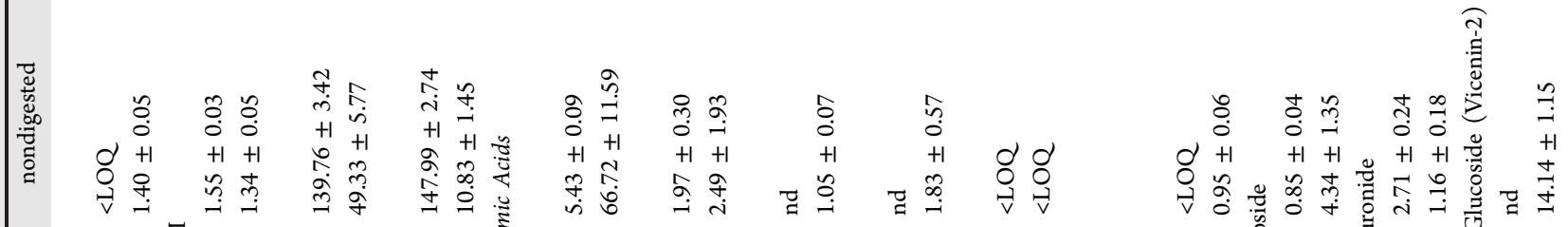

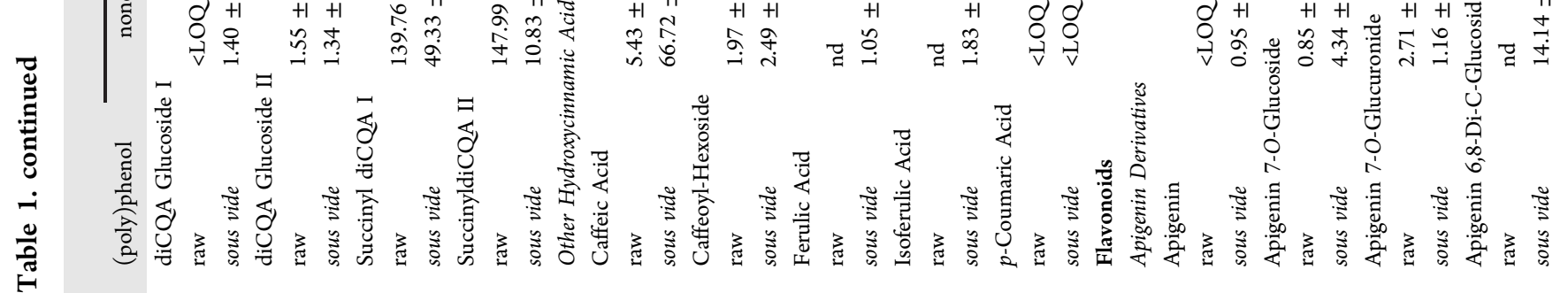




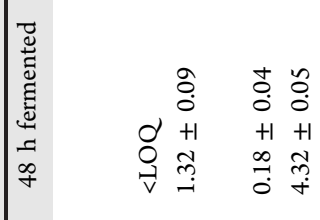

$\vec{g}$

$\exists \square$

$\vec{G} \quad \bar{G} \cdot \vec{g}$

$\vec{g} \cdot$

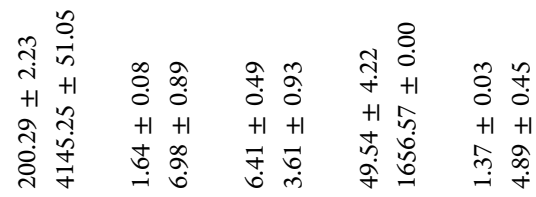

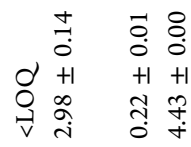

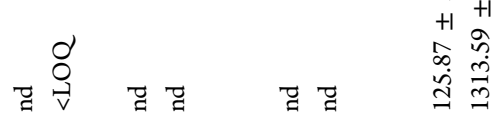

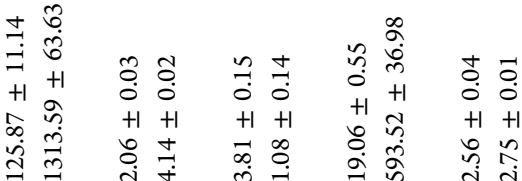

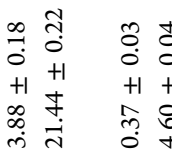

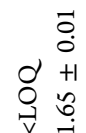

\pm สุ

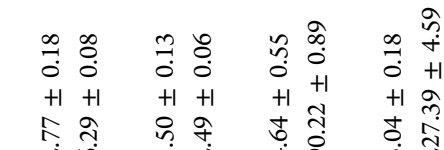

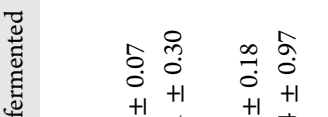

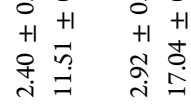

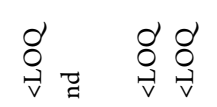

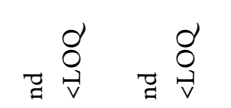

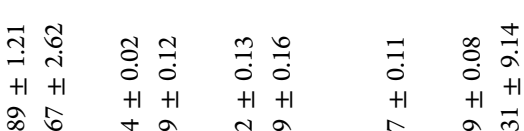

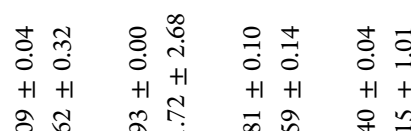

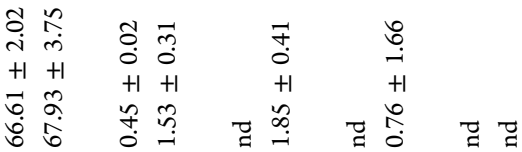

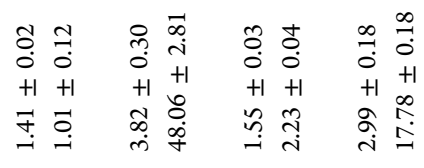

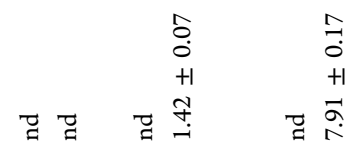

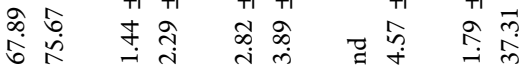

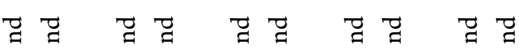

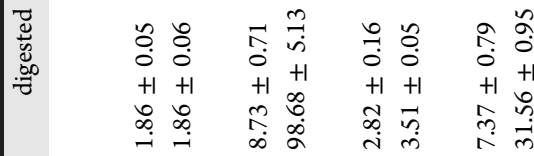

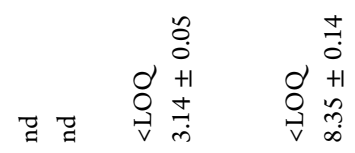

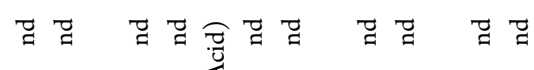

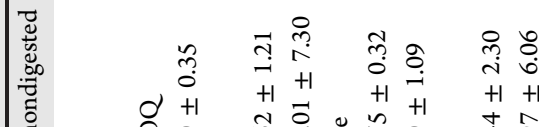

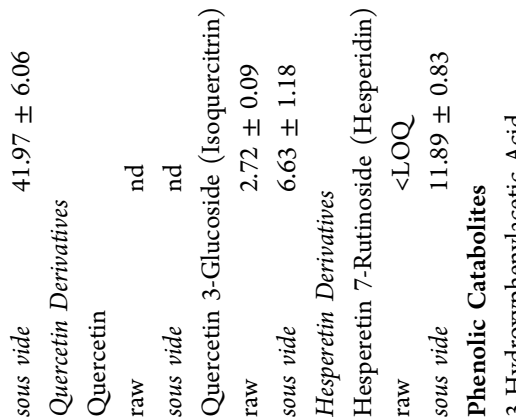

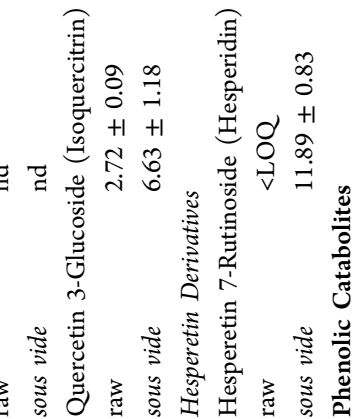

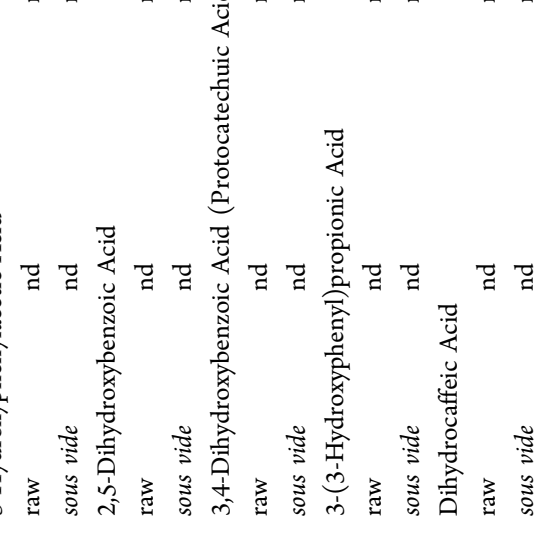


upon further fermentation. Both phenolic acids and flavonoids were mainly catabolized during the first $8 \mathrm{~h}$ of colonic fermentation, remaining bioaccessible for $0.1-2.2 \%$ of phenolic acids and 4.1-16.9\% of flavonoids (Table 2). During the first $4 \mathrm{~h}$ of colonic fermentation, five catabolites were detected [i.e., 3-hydroxyphenylacetic, 2,5-dihydroxybenzoic, protocatechuic, 3-(3-hydroxyphenyl)propionic and dihydrocaffeic acids], and their contents gradually increased throughout the $48 \mathrm{~h}$ of colonic fermentations, except for dihydrocaffeic acid whose content diminished after $8 \mathrm{~h}$ (Table 1). The catabolite 4-hydroxybenzoic acid was produced after 8 $\mathrm{h}$ of fermentation of both samples; and phenylacetic acid and 1,2-dihydroxybenzene were produced after $24 \mathrm{~h}$. Small amounts of 3-hydroxybenzoic acid were quantified at $48 \mathrm{~h}$ of fermentation of both raw and sous-vide-cooked cardoon. The highest total content of catabolites occurred after $48 \mathrm{~h}$ of fermentation of both raw and sous-vide-cooked red cardoon ( 863.13 and $5899 \mu \mathrm{g} / \mathrm{g} \mathrm{dm}$, respectively) (Table 2). Finally, the total content of catabolites was higher in sous vide than in raw cardoon at different time points (1.7-fold at $4 \mathrm{~h}, 5.8$-fold at $8 \mathrm{~h}, 8$-fold at $24 \mathrm{~h}$, and 6.8 -fold at $48 \mathrm{~h}$ ) (Table 2), mainly due to the increase of the most abundant catabolites [3hydroxyphenylacetic and 3-(3-hydroxyphenyl)propionic acids] (Table 1).

In Vitro Anti-inflammatory Activity. The anti-inflammatory activity in the small intestine was evaluated by measuring the impact of GI-digested raw and sous vide cardoon on basal and LPS-stimulated cytokine secretion in differentiated Caco-2 cells. GI-digested raw red cardoon neither significantly modified the basal secretion of the tested cytokines (IL-8, IL-6, IL- $1 \beta$, TNF- $\alpha$, and IL-10) in cells at any of the concentrations (i.e., 2.42 and $9.68 \mathrm{mg} \mathrm{dm} / \mathrm{mL}$ ), as compared to the control (untreated cells) (Figure $1 \mathrm{a}-\mathrm{e}$ ), nor did the digested sous-vide-cooked cardoon induced significant differences in the basal secretion of the tested cytokines at $2.42 \mathrm{mg}$ $\mathrm{dm} / \mathrm{mL}$ but caused a significant increase of IL- $8(p<0.001)$, IL-1 $\beta(p=0.001)$, TNF- $\alpha(p=0.002)$, and IL-10 $(p<0.001)$ at $9.68 \mathrm{mg} \mathrm{dm} / \mathrm{mL}$, as compared to control. In addition, the increased secretion of IL- $1 \beta$ and TNF- $\alpha$ induced by digested sous-vide-cooked cardoon at $9.68 \mathrm{mg} \mathrm{dm} / \mathrm{mL}$ was not significantly different to that caused by LPS.

Differentiated Caco- 2 cells stimulated with $5 \mu \mathrm{g} / \mathrm{mL}$ LPS for $48 \mathrm{~h}$ (called "control + LPS") showed a significant rise in IL-8, IL-6, TNF- $\alpha$, IL-10 ( $p<0.001)$, and IL-1 $\beta(p=0.001)$ secretions (Figure 1a-e). Control + LPS was used as the control to assess the impact of GI-digested cardoon on the LPS-induced secretion of cytokines. At $2.42 \mathrm{mg} \mathrm{dm} / \mathrm{mL}$, digested raw cardoon significantly decreased the LPS-induced secretion of IL-8 $(p=0.020)$, whereas at $9.68 \mathrm{mg} \mathrm{dm} / \mathrm{mL}$ it induced a significant reduction in the LPS-induced secretion of IL-8 $(p<0.001)$, IL-6 $(p=0.026)$, TNF- $\alpha(p=0.014)$, and IL$10(p=0.004)$ to levels that were not significantly different from the control without LPS stimulation. On the contrary, digested sous-vide-cooked red cardoon did not significantly change the LPS-induced secretion of IL-8, IL-6, IL- $1 \beta$, TNF- $\alpha$, or IL-10 at the tested concentrations.

The anti-inflammatory activity in the colon was evaluated by measuring the impact of GI-digested and colonic-fermented raw and sous vide cardoon on basal and LPS-stimulated cytokine secretion in HT-29 cells. Untreated HT-29 cells were used as the blank control (called "control"), and cells incubated with supernatants from 8 or $24 \mathrm{~h}$ NFC were used as a carrier control (called "NFC") for the assessment of the 
Table 2. Total (Poly)phenols and Phenolic Catabolites from Raw and Sous-Vide-Cooked Red Cardoon before and after Simulated Oral GI Digestion In Vitro, after Subsequent Dialysis and during a Simulated Colonic Fermentation In Vitro (0, 8, 24, and $48 \mathrm{~h}$ ), as Analyzed by HPLC-MS/MS ${ }^{a}$

\begin{tabular}{|c|c|c|c|c|c|c|c|c|}
\hline \multirow[t]{2}{*}{$\begin{array}{l}\text { (poly) } \\
\text { phenol }\end{array}$} & \multicolumn{8}{|c|}{ red cardoon } \\
\hline & nondigested & digested & $\begin{array}{l}\text { digested and } \\
\text { dialyzed }\end{array}$ & $0 \mathrm{~h}$ fermented & $4 \mathrm{~h}$ fermented & $8 \mathrm{~h}$ fermented & $\begin{array}{c}24 \mathrm{~h} \\
\text { fermented }\end{array}$ & $\begin{array}{c}48 \mathrm{~h} \\
\text { fermented }\end{array}$ \\
\hline \multicolumn{9}{|c|}{ Phenolic Acids } \\
\hline \multicolumn{9}{|c|}{ Monocaffeoylquinic Acids (CQAs) and Derivatives } \\
\hline raw & 5707.33 & $55.27(1 \%)$ & $41.04(0.7 \%)$ & $29.10(0.5 \%)$ & $15.60(0.3 \%)$ & $16.73(0.3 \%)$ & $0.78(<0.1 \%)$ & $0.19(<0.1 \%)$ \\
\hline Sous vide & 6402.44 & $4393.86(68.6 \%)$ & $3318.66(51.8 \%)$ & $2035.07(31.8 \%)$ & $1560.62(24.4 \%)$ & $37.56(0.6 \%)$ & $6.82(0.1 \%)$ & $0.82(<0.1 \%)$ \\
\hline \multicolumn{9}{|c|}{ Dicaffeoylquinic Acids (diCQAs) and Derivatives } \\
\hline raw & 7308.38 & $13.09(0.2 \%)$ & $8.00(0.1 \%)$ & $3.51(<0.1 \%)$ & $1.11(<0.1 \%)$ & $1.01(<0.1 \%)$ & $<\mathrm{LOQ}$ & $<\mathrm{LOQ}$ \\
\hline Sous vide & 6464.06 & $3295.71(51 \%)$ & $1602.48(24.8 \%)$ & $794.63(12.3 \%)$ & $760.73(11.8 \%)$ & $251.38(3.9 \%)$ & $6.43(0.1 \%)$ & $2.33(<0.1 \%)$ \\
\hline \multicolumn{9}{|c|}{ Other Hydroxycinnamic Acids } \\
\hline raw & 7.40 & $1.01(13.6 \%)$ & $1.16(15.7 \%)$ & $0.49(6.7 \%)$ & $2.92(39.4 \%)$ & $<\mathrm{LOQ}$ & $<\mathrm{LOQ}$ & $<\mathrm{LOQ}$ \\
\hline Sous vide & 72.09 & $8.20(11.4 \%)$ & $1.60(2.2 \%)$ & $7.39(10.3 \%)$ & $49.27(68.4 \%)$ & $1.30(1.8 \%)$ & 2.76 & 2.02 \\
\hline \multicolumn{9}{|c|}{ Total phenolic Acids } \\
\hline raw & $13,023.11$ & $69.37(0.5 \%)$ & $50.21(0.4 \%)$ & $33.10(0.3 \%)$ & $19.63(0.2 \%)$ & $17.74(0.1 \%)$ & $0.78(<0.1 \%)$ & $0.19(<0.1 \%)$ \\
\hline Sous vide & $12,938.58$ & $7697.77(59.5 \%)$ & $4922.74(38 \%)$ & $2837.09(21.9 \%)$ & $2370.62(18.3 \%)$ & $290.24(2.2 \%)$ & $16.01(0.1 \%)$ & $5.17(<0.1 \%)$ \\
\hline \multicolumn{9}{|c|}{ Flavonoids } \\
\hline \multicolumn{9}{|c|}{ Apigenin Derivatives } \\
\hline raw & 3.56 & $2.68(75.3 \%)$ & $0.74(20.8 \%)$ & $<\mathrm{LOQ}$ & $<$ LOQ & $0.98(27.5 \%)$ & $<\mathrm{LOQ}$ & $<\mathrm{LOQ}$ \\
\hline Sous vide & 20.59 & $14.13(68.6 \%)$ & $5.98(29 \%)$ & $4.20(20.4 \%)$ & $4.14(20.1 \%)$ & $3.65(17.8 \%)$ & $<\mathrm{LOQ}$ & $<\mathrm{LOQ}$ \\
\hline \multicolumn{9}{|c|}{ Luteolin Derivatives } \\
\hline raw & 119.81 & $20.77(17.3 \%)$ & $9.77(8.2 \%)$ & $7.23(6 \%)$ & $5.32(4.4 \%)$ & $4.24(3.5 \%)$ & $0.22(0.2 \%)$ & $0.18(0.2 \%)$ \\
\hline Sous vide & 158.58 & $135.60(85.5 \%)$ & $69.08(43.6 \%)$ & $50.08(31.6 \%)$ & $28.55(18 \%)$ & $26.04(16.4 \%)$ & $7.41(4.7 \%)$ & $5.64(3.6 \%)$ \\
\hline \multicolumn{9}{|c|}{ Quercetin Derivatives } \\
\hline raw & 2.72 & $<$ LOQ & 0.00 & 0.00 & 0.00 & $<$ LOQ & 0.00 & 0.00 \\
\hline Sous vide & 6.63 & $3.14(47.3 \%)$ & $1.42(21.4 \%)$ & $<$ LOQ & $<$ LOQ & $1.65(24.9 \%)$ & $<$ LOQ & 0.00 \\
\hline \multicolumn{9}{|c|}{ Total Flavonoids } \\
\hline raw & 126.09 & $23.45(18.6 \%)$ & $10.51(8.3 \%)$ & $7.23(5.7 \%)$ & $5.32(4.2 \%)$ & $5.22(4.1 \%)$ & $0.22(0.2 \%)$ & $0.18(0.1 \%)$ \\
\hline Sous vide & 197.70 & $161.21(82.3 \%)$ & $84.39(41.2 \%)$ & $54.28(29.2 \%)$ & $32.68(17.6 \%)$ & $31.34(16.9 \%)$ & $7.41(4 \%)$ & $5.64(3 \%)$ \\
\hline \multicolumn{9}{|c|}{ Total (Poly)phenols } \\
\hline raw & $13,149.20$ & $92.82(0.7 \%)$ & $60.72(0.5 \%)$ & $40.33(0.3 \%)$ & $24.95(0.2 \%)$ & $22.96(0.2 \%)$ & $1.00(<0.1 \%)$ & $0.37(<0.1 \%)$ \\
\hline Sous vide & $13,136.28$ & $7858.98(59.8 \%)$ & $5007.13(38.1 \%)$ & $2891.37(22 \%)$ & $2403.30(18.3 \%)$ & $321.58(2.5 \%)$ & $23.42(0.2 \%)$ & $10.81(0.1 \%)$ \\
\hline \multicolumn{9}{|c|}{ Phenolic Catabolites } \\
\hline raw & 0.00 & 0.00 & 0.00 & 67.05 & 73.95 & 100.84 & 238.22 & 863.13 \\
\hline Sous vide & 0.00 & 0.00 & 0.00 & 72.08 & 123.73 & 584.65 & 1918.16 & 5899.00 \\
\hline
\end{tabular}

${ }^{a}$ Results are expressed as total $\mu \mathrm{g}$ (poly)phenolic compound per $\mathrm{g}$ red cardoon sample dry matter. Total (poly)phenol bioaccessibility (\%) is included in brackets. $\angle \mathrm{LOQ}$ below the limit of quantification.

anti-inflammatory activity of 8 and $24 \mathrm{~h}$ colonic fermented raw and sous-vide-cooked red cardoon. NFC of either $8 \mathrm{~h}$ (Figure 2) or 24 h (Figure 3) colonic fermentation generally induced a significant stimulation of the basal cytokine secretion in the HT-29 cells as compared to the control $(p<0.05)$. Neither 8 nor $24 \mathrm{~h}$ fermented raw and sous-vide-cooked cardoon changed the cytokine secretion stimulated by NFC at the tested concentrations $(23.8$ and $95.3 \mu \mathrm{g} \mathrm{dm} / \mathrm{mL}$ ).

HT-29 cells treated with $0.1 \mu \mathrm{g} / \mathrm{mL}$ of LPS for $48 \mathrm{~h}$ (called "control + LPS") induced a highly significant increase $(p<$ $0.001)$ of all the tested cytokines with respect to the control (Figures 2 and 3). Co-treatment of NFC from either $8 \mathrm{~h}$ (Figure 2) or $24 \mathrm{~h}$ (Figure 3) colonic fermentation and LPS $(\mathrm{NFC}+\mathrm{LPS})$ showed no differences in IL-8, IL-6, IL-1 $\beta$, TNF- $\alpha$, and IL-10 secretions with respect to control + LPS. Neither raw nor sous-vide-cooked red cardoon, either 8 or $24 \mathrm{~h}$ colonic fermented, showed significant differences in the cytokine secretion with respect to control + LPS or NFC + LPS at the tested concentrations (23.8 and $95.3 \mu \mathrm{g} \mathrm{dm} / \mathrm{mL}$ ). No significant differences were found between fermented raw and sous vide cardoon in their impact on the basal and LPSinduced secretion of the tested cytokines in HT-29 cells (Figures 2 and 3).

In Vitro Prebiotic Activity. Impact on the Growth of Selected Bacterial Populations of Gut Microbiota. The fermentation of sous-vide-cooked cardoon significantly ( $p<$ 0.05) enhanced the growth of Bifidobacterium spp. after 8, 24, and $48 \mathrm{~h}$ of fermentation compared to the baseline and NFC (Figure 4a). This bifidogenic effect was similar to that observed with the positive control FOS at the end of the fermentation $(1.08 \pm 0.04$ and $1.14 \pm 0.02 \log 10$ bacterial counts of bifidobacteria after $48 \mathrm{~h}$ of FOS and sous-vide-cooked cardoon fermentations, respectively, relative to the baseline). Raw cardoon also induced the stimulation of bifidobacteria, which was close to reaching statistical significance compared to $\mathrm{NFC}$ at $48 \mathrm{~h}(p=0.052)(1.08 \pm 0.06$ and $0.97 \pm 0.02 \log 10$ bacterial counts of bifidobacteria after $48 \mathrm{~h}$ of raw cooked cardoon fermentations and NFC, respectively, relative to the baseline). Moreover, numbers of Lactobacillus/Enterococcus were also significantly increased after $24 \mathrm{~h}$ of fermentation with 
(a)

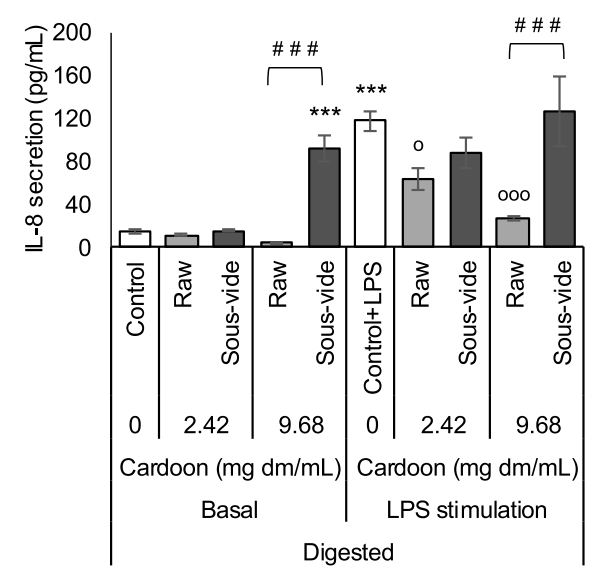

(c)

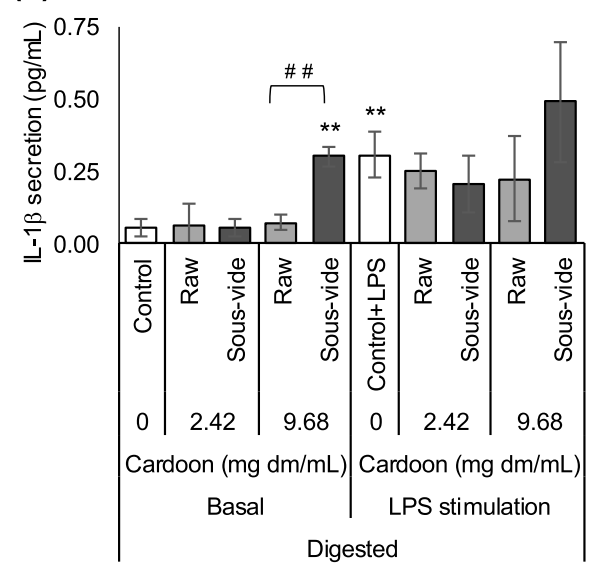

(e)

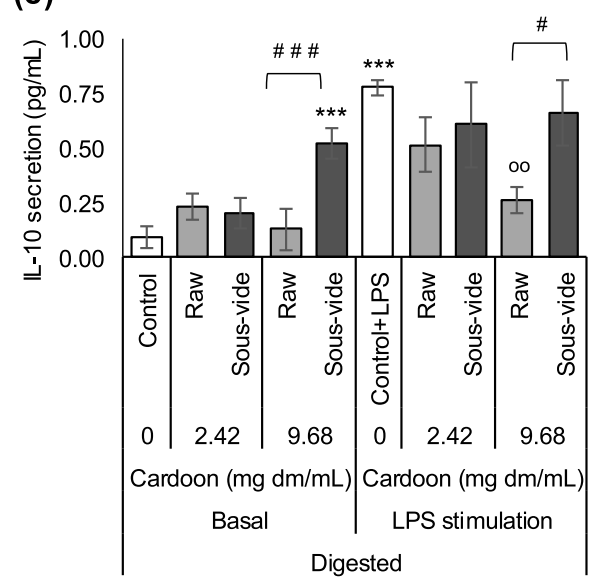

(b)

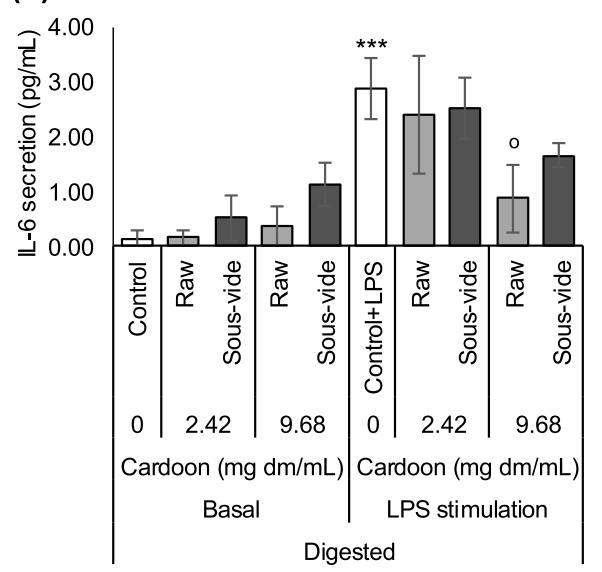

(d)

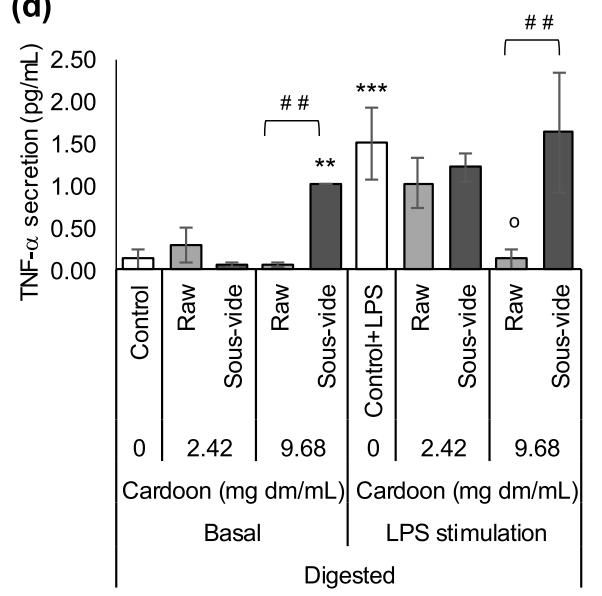

Figure 1. Impact of the digested raw and sous vide red cardoon on basal and LPS-induced secretion of cytokines (a) IL-8, (b) IL-6, (c) IL-1 $\beta$, (d) TNF- $\alpha$, and (e) IL-10 in differentiated Caco- 2 cells (Luminex multiplex assay). Cells were pretreated with supernatants of the digested cardoon samples for $1 \mathrm{~h}$, and treatment was continued for further $48 \mathrm{~h}$ in the absence or presence of $5 \mu \mathrm{g} / \mathrm{mL}$ LPS. Results are expressed as the mean of picograms of cytokine secretion per milliliter $(\mathrm{pg} / \mathrm{mL}) \pm \mathrm{SD}(n=3$ experiments $) .{ }^{*} p<0.05, * * p<0.01$, and $* * * p<0.001$ indicate significantly different from control (untreated cells). ${ }^{\circ} p<0.05$, ${ }^{\circ o} p<0.01$, and ${ }^{\circ o o} p<0.001$ indicate significantly different from control + LPS. ${ }^{\#} p<0.05$, ${ }^{\# \#} p<$ 0.01 , and ${ }^{\# \#} p<0.001$ indicate significant differences among raw and sous vide cardoon.

raw and sous-vide-cooked cardoon $(p=0.003$ and $p=0.004$, respectively) and FOS $(p=0.003)$. This stimulation still persisted after $48 \mathrm{~h}$ of fermentation with raw cardoon ( $p=$ 0.043) (Figure $4 \mathrm{~b}$ ). Increases of E. rectale-C. coccoides were also detected with raw cardoon and FOS fermentations at $48 \mathrm{~h}$ compared to NFC ( $p=0.040$ and 0.017) (Figure 4c). A significant stimulation of Bacteroides-Prevotella spp. was observed at $8 \mathrm{~h}$ of raw cardoon fermentation $(p=0.019)$ and at 8 and 24 h of sous-vide-cooked cardoon ( $p=0.018$ and $0.023)$ and FOS $(p=0.009$ and 0.019$)$ fermentations compared with NFC (Figure 4d). Bacteroides-Prevotella spp. showed the highest growth during fermentation when compared with the other tested populations of gut microbiota. There was no significant change in the total bacterial numbers with sous-vide-cooked cardoon and FOS, while a significant 
(a)

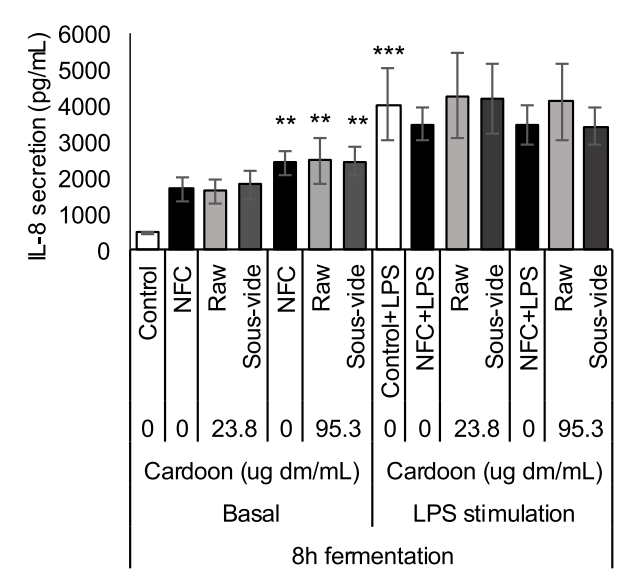

(c)

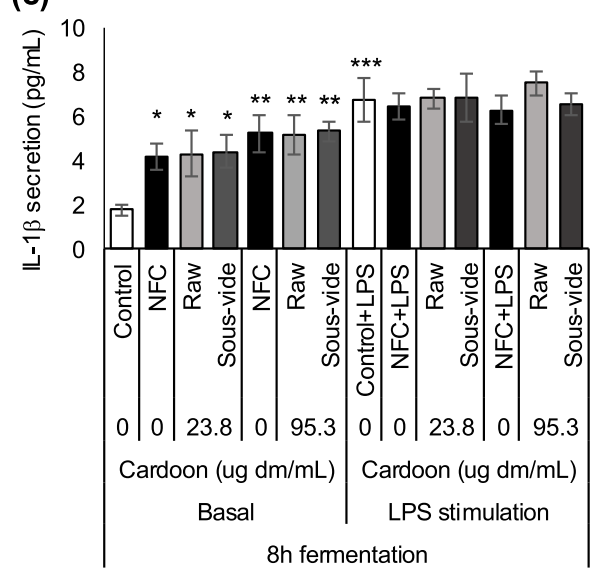

(e)

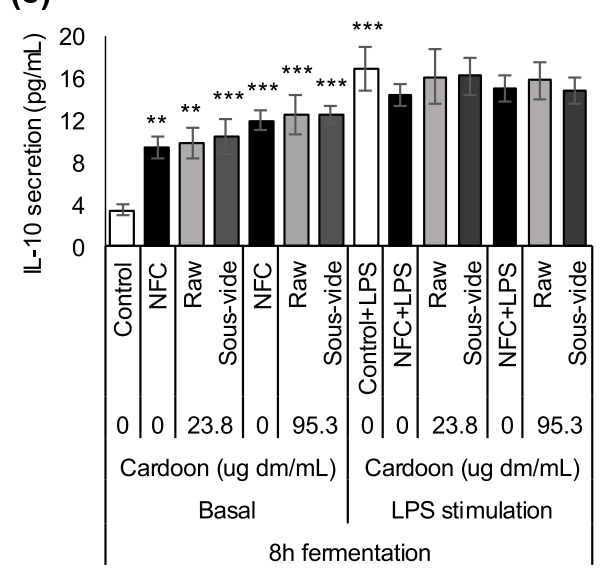

(b)

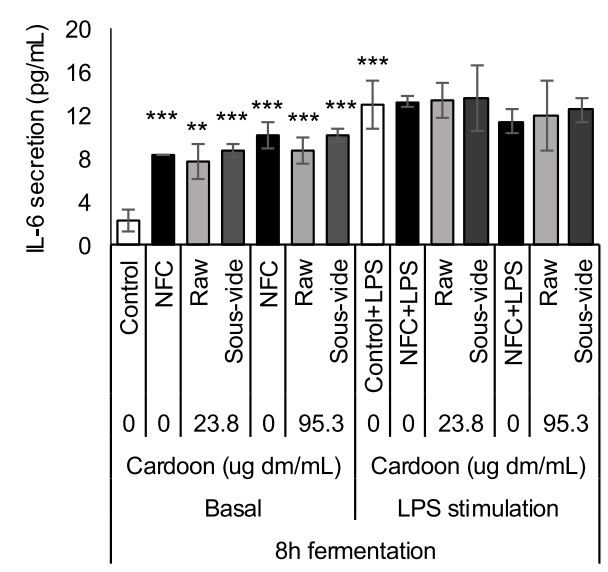

(d)

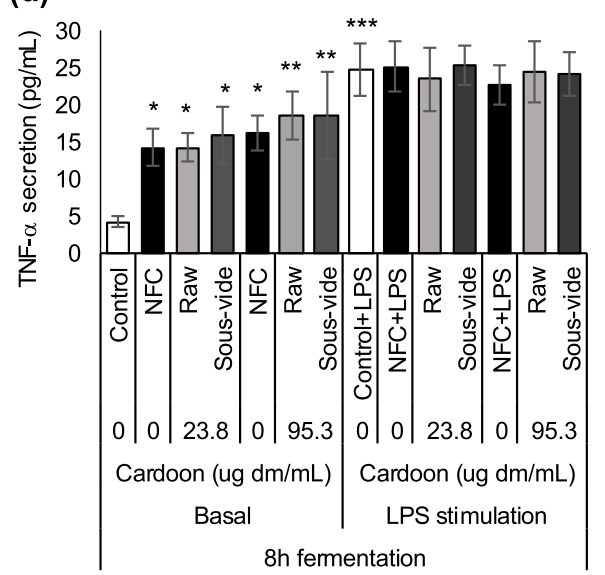

Figure 2. Impact of $8 \mathrm{~h}$ fermented raw and sous vide red cardoon on basal and LPS-induced secretion of cytokines (a) IL-8, (b) IL-6, (c) IL-1 $\beta$, (d) TNF- $\alpha$, and (e) IL-10 in HT-29 cells (Luminex multiplex assay). Cells were pretreated with supernatants from $8 \mathrm{~h}$ fermentation of cardoon samples or NFC at 0.25 or $1 \% \mathrm{v} / \mathrm{v}$ for $1 \mathrm{~h}$, and treatment was continued for further $48 \mathrm{~h}$ in the absence or presence of $0.1 \mu \mathrm{g} / \mathrm{mL} \mathrm{LPS}$. Results are expressed as the mean of picograms of cytokine secretion per milliliter $(\mathrm{pg} / \mathrm{mL}) \pm \operatorname{SD}(n=3$ experiments). $* p<0.05$, $* * p<0.01$, and $* * * p<$ 0.001 indicate significantly different from control (untreated cells). Lack of asterisk indicates nonsignificant differences ( $p \geq 0.05)$ (both in comparison with control and NFC values, either with or without LPS stimulation, and between raw and sous vide cardoon).

increase was observed at $8 \mathrm{~h}$ of raw cardoon fermentation $(p=$ 0.046) (Figure 4e).

Impact on Lactic Acid and SCFA Production by Gut Microbiota. Significant increases of acetate were detected during the fermentation of raw and sous-vide-cooked cardoon compared to the baseline $(0 \mathrm{~h})$ and NFC $(p<0.05)$ (Table 3$)$. The highest concentration of acetate was detected at $48 \mathrm{~h}$ of fermentation with raw cardoon and FOS and at 24 and $48 \mathrm{~h}$ of fermentation with sous-vide-cooked cardoon. Propionate was the second more abundant SCFA produced during the fermentation of FOS and cardoon samples (Table 3). Similar to acetate, propionate production showed an increasing trend during fermentation but the highest increase occurred from $8 \mathrm{~h}$ to $24 \mathrm{~h}$ of fermentation of cardoon samples. The propionate 
(a)

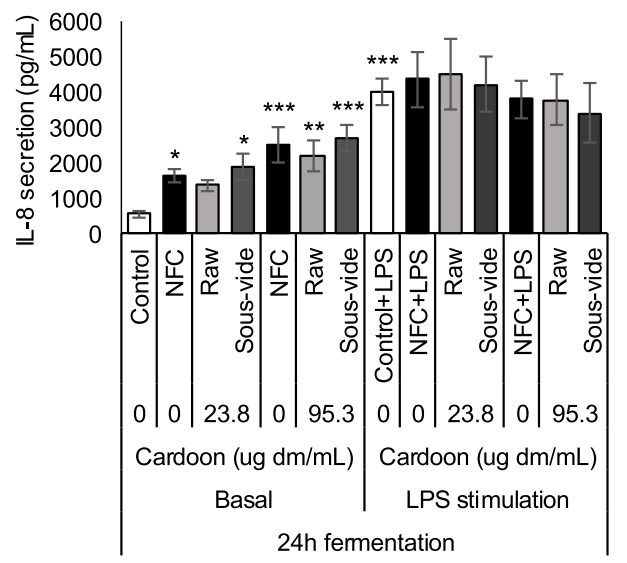

(c)

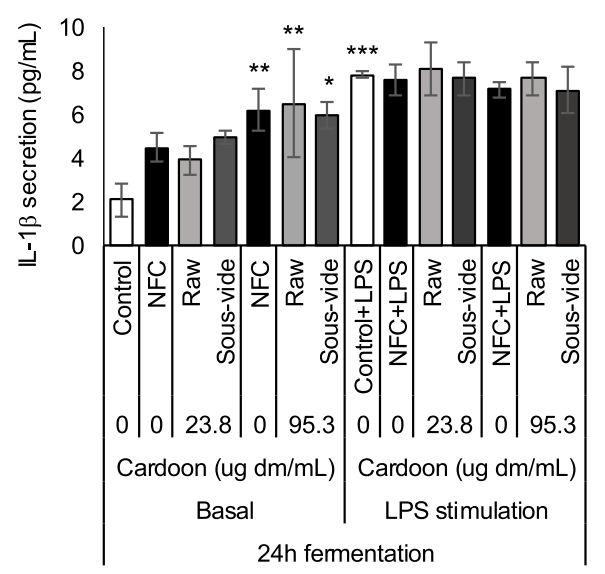

(e)

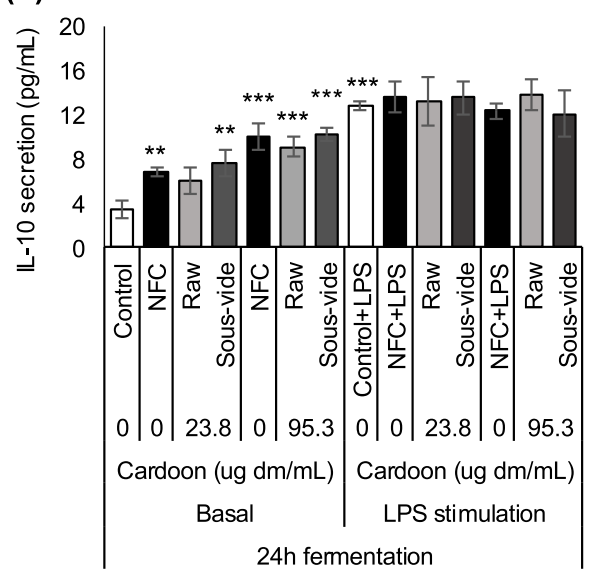

(b)

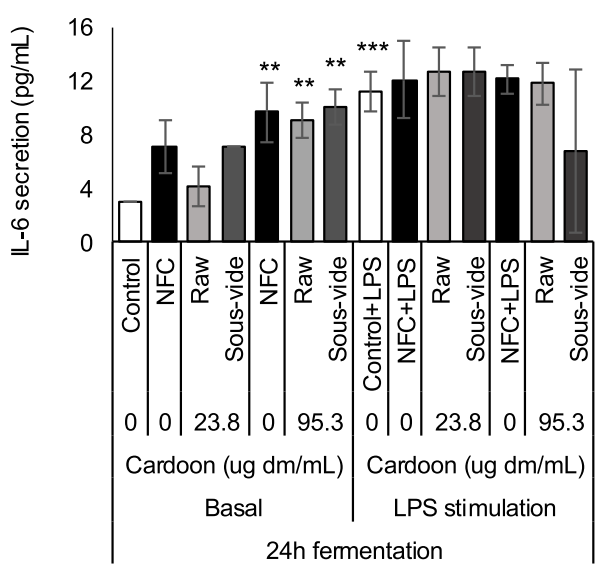

(d)

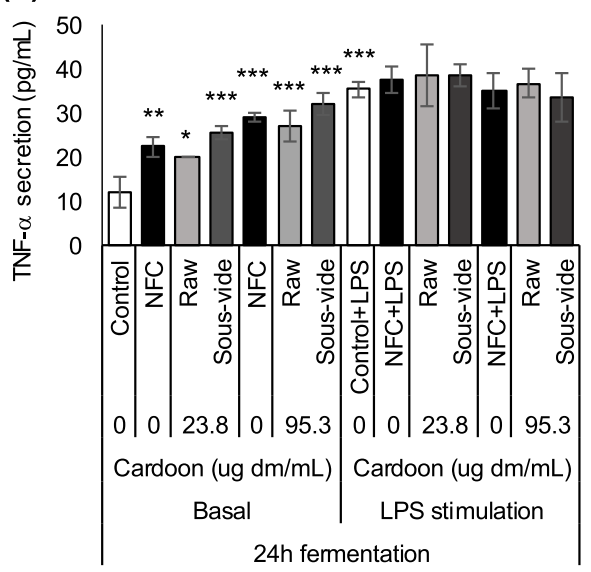

Figure 3. Impact of $24 \mathrm{~h}$ fermented raw and sous vide red cardoon on the basal and LPS-induced secretion of cytokines (a) IL-8, (b) IL-6, (c) IL$1 \beta$, (d) TNF- $\alpha$, and (e) IL-10 in HT-29 cells (Luminex multiplex assay). Cells were pretreated with supernatants from $24 \mathrm{~h}$ of fermentation of cardoon samples or NFC at 0.25 or $1 \% \mathrm{v} / \mathrm{v}$ for $1 \mathrm{~h}$, and treatment was continued for further $48 \mathrm{~h}$ in the absence or presence of $0.1 \mu \mathrm{g} / \mathrm{mL} \mathrm{LPS}$. Results are expressed as the mean of picograms of cytokine secretion per milliliter $(\mathrm{pg} / \mathrm{mL}) \pm \mathrm{SD}(n=3$ experiments $)$. * $p<0.05$, ** $p<0.01$, and $* * * p<0.001$ indicate significantly different from control (untreated cells). Lack of asterisk indicates nonsignificant differences ( $p \geq 0.05)$ (both in comparison with control and NFC values, either with or without LPS stimulation, and between raw and sous vide cardoon).

concentration from raw and sous-vide-cooked cardoon fermentations was not significantly higher than that in NFC at any time point, and it reached a statistical significance after $48 \mathrm{~h}$ of FOS fermentation $(p=0.003)$. Although the production of butyrate was lower than acetate and propionate, a slight but significant increase in the butyrate concentration was observed at 24 and $48 \mathrm{~h}$ of fermentation with raw and sous- vide-cooked cardoon compared to the baseline $(0 \mathrm{~h})(p<$ $0.05)$. However, this increase did not reach a statistical significance compared to NFC. The highest amount of butyrate was detected with FOS after $48 \mathrm{~h}$ of fermentation and this increase was significant compared to NFC ( $p=$ 0.014). The lactate concentration was very low in all the samples and did not reach a statistical significance compared to 
(a)

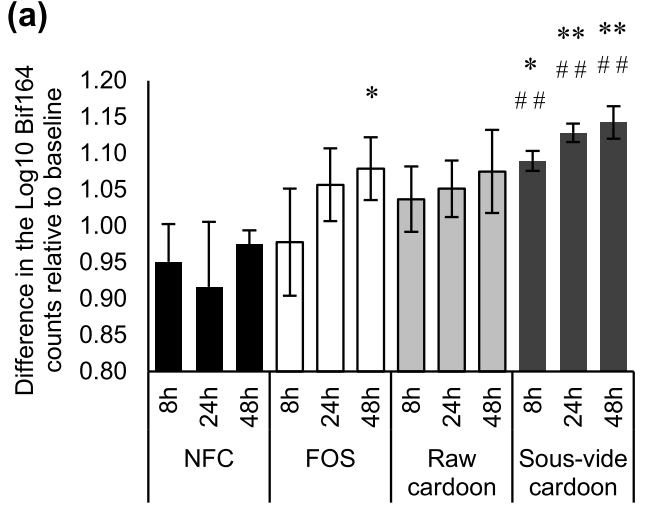

(c)

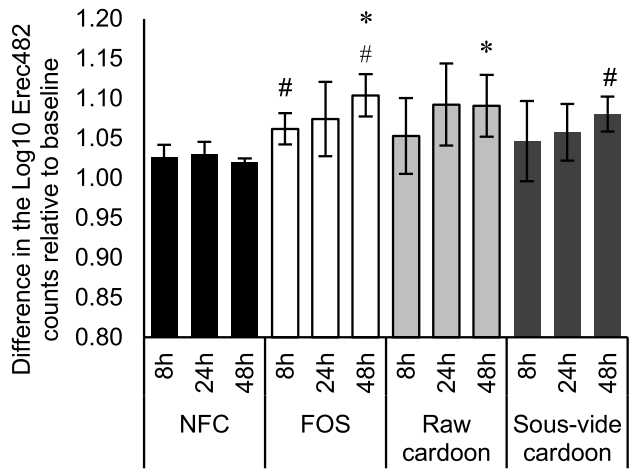

(b)

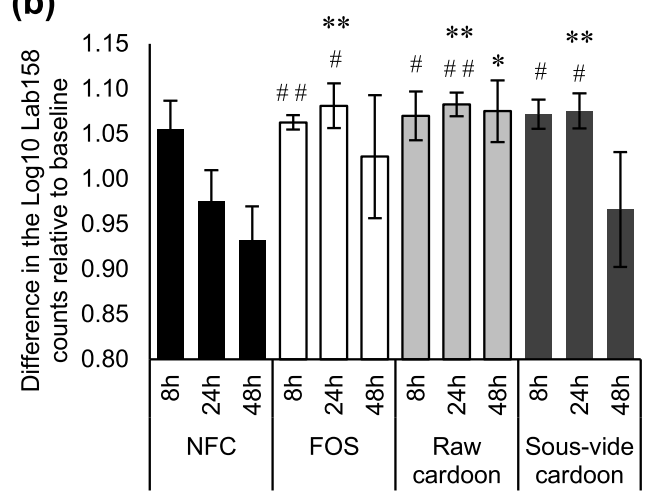

(d)

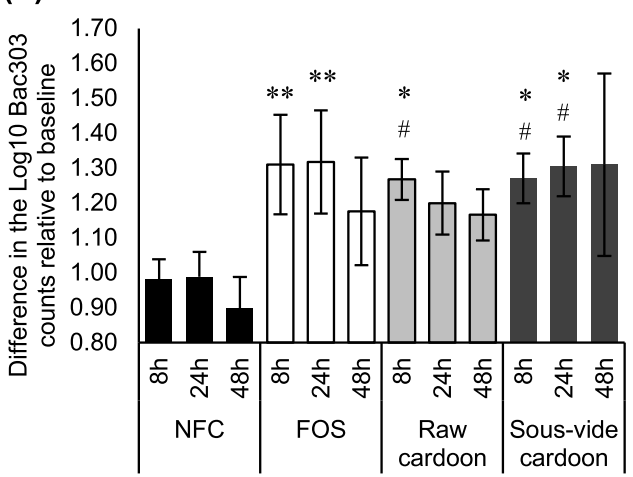

(e)

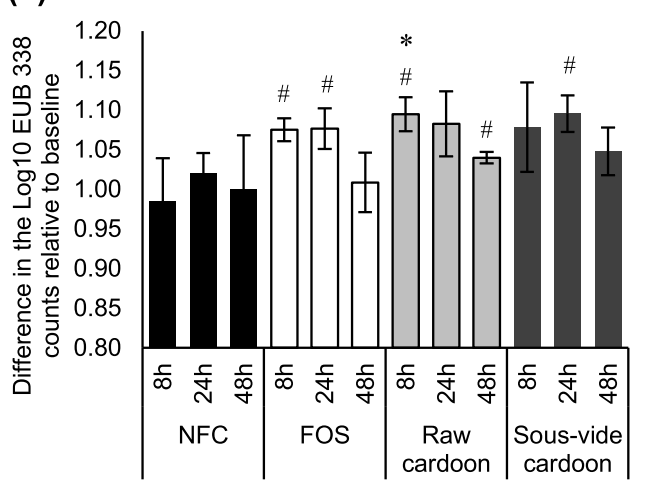

Figure 4. Impact of raw and sous vide red cardoon on the growth of specific bacterial populations (a) Bifidobacterium spp. (Bif164), (b) Lactobacillus/Enterococcus spp. (Lab158), (c) E. rectale-C. coccoides group (Erec482), (d) Bacteroides-Prevotella group (Bac303), and (e) total bacteria (EUB 338), at 8, 24, or $48 \mathrm{~h}$ of in vitro batch-cultured colonic fermentation, as analyzed by FISH. NFC and prebiotic FOS are included. Results are expressed as the mean of the difference in the $\log 10$ bacterial counts of each specific bacteria relative to the baseline $(0 \mathrm{~h}) \pm \mathrm{SD}(n=3$ experiments). $* p<0.05, * * p<0.01$, and $* * * p<0.001$ indicate significantly different from NFC at the same time point. \#p $<0.05$ and \#\#p $<0.01$ indicate significantly different from the baseline within the same treatment.

NFC (Table 3). Concentrations of isobutyric and isovaleric acids were either below the detection limit or, in many cases, were detected only in a single donor (data not shown). The concentration of total SCFAs increased significantly $(p<0.05)$ at 8,24 , and $48 \mathrm{~h}$ of FOS fermentation, and in the case of raw and sous-vide-cooked cardoon fermentation at $48 \mathrm{~h}$ compared to NFC $(p<0.05)$. The highest concentrations of total SCFAs were found at $48 \mathrm{~h}$ of fermentation of FOS and cardoon samples, mainly due to acetate production but also propionate production. No significant differences were found between raw and sous-vide-cooked cardoon regarding their impact on lactic acid and SCFA production.

\section{DISCUSSION}

The application of culinary heat treatments to (poly)phenolicrich plant foods, such as cultivated cardoon stalks, induces wall and cell ruptures and consequently the release of those (poly)phenols bound to the food matrix. ${ }^{3,20}$ However, some (poly)phenols remained linked to other macromolecules, such as dietary fiber during boiling, ${ }^{21,22}$ or are included into melanoidin structures when formed at high temperatures. ${ }^{23,24}$ Moreover, the inactivation of polyphenol oxidases by heat inhibits (poly)phenol degradation, and the use of little water and vacuum bags in the sous vide cooking avoids the (poly)phenols leaching into the water. All these reasons may explain the similar total content of (poly)phenols in raw and sous-vide-cooked red cardoon. After GI digestion, (poly)phenols were almost totally degraded by the digestive enzymes 
Table 3. Impact of Raw and Sous-Vide-Cooked Red Cardoon on the Production of Major SCFAs (Acetic, Propionic, and Butyric Acids) and Lactic Acid at Different Time Points (0, 8, 24, and 48 h) of In Vitro Colonic Fermentation, as Analyzed by GC-FID $^{a}$

\begin{tabular}{|c|c|c|c|c|}
\hline SCFA & NFC & FOS & raw cardoon & sous vide-cooked cardoon \\
\hline \multicolumn{5}{|c|}{ Acetate } \\
\hline $0 \mathrm{~h}$ & $0.29 \pm 0.29$ & $0.26 \pm 0.26$ & $1.24 \pm 0.07^{*}$ & $1.59 \pm 0.05 * *$ \\
\hline $8 \mathrm{~h}$ & $4.88 \pm 1.48$ & $17.68 \pm 1.51 \# \# * *$ & $16.65 \pm 1.38 \# \# * *$ & $19.91 \pm 0.64 \# \# * * *$ \\
\hline $24 \mathrm{~h}$ & $6.96 \pm 4.49$ & $32.28 \pm 3.63 \# * *$ & $25.27 \pm 3.89 \# \# *$ & $33.41 \pm 2.84 \# \# * *$ \\
\hline $48 \mathrm{~h}$ & $8.67 \pm 4.68$ & $38.77 \pm 2.69 \# \# * *$ & $34.22 \pm 2.92 \# * *$ & $33.76 \pm 4.69 \# * *$ \\
\hline \multicolumn{5}{|c|}{ Propionate } \\
\hline $0 \mathrm{~h}$ & nd & nd & nd & $\mathrm{Nd}$ \\
\hline $8 \mathrm{~h}$ & $1.02 \pm 0.52$ & $5.40 \pm 4.06$ & $2.75 \pm 0.93$ & $2.64 \pm 0.80$ \\
\hline $24 \mathrm{~h}$ & $1.61 \pm 0.92$ & $14.48 \pm 7.13$ & $9.80 \pm 3.25$ & $12.92 \pm 4.72$ \\
\hline $48 \mathrm{~h}$ & $2.14 \pm 1.00$ & $26.80 \pm 2.39 \# \# * *$ & $11.65 \pm 2.89$ & $12.81 \pm 5.28$ \\
\hline \multicolumn{5}{|c|}{ Butyrate } \\
\hline $0 \mathrm{~h}$ & nd & nd & nd & $\mathrm{Nd}$ \\
\hline $8 \mathrm{~h}$ & $0.36 \pm 0.35$ & $0.87 \pm 0.44$ & $0.10 \pm 0.10$ & $0.10 \pm 0.10$ \\
\hline $24 \mathrm{~h}$ & $0.52 \pm 0.52$ & $3.94 \pm 1.76$ & $1.74 \pm 0.46 \#$ & $1.35 \pm 0.15 \#$ \\
\hline $48 \mathrm{~h}$ & $1.05 \pm 0.61$ & $6.83 \pm 1.81^{*}$ & $2.06 \pm 0.36 \#$ & $1.70 \pm 0.36 \#$ \\
\hline \multicolumn{5}{|c|}{ Lactate } \\
\hline $0 \mathrm{~h}$ & nd & nd & nd & $\mathrm{Nd}$ \\
\hline $8 \mathrm{~h}$ & $2.17 \pm 2.16$ & $3.01 \pm 0.52 \#$ & $3.42 \pm 1.05$ & $4.71 \pm 1.92$ \\
\hline $24 \mathrm{~h}$ & $0.01 \pm 0.00$ & $6.76 \pm 5.18$ & $2.10 \pm 2.10$ & $2.30 \pm 2.30$ \\
\hline $48 \mathrm{~h}$ & nd & nd & $1.60 \pm 1.60$ & $2.07 \pm 2.07$ \\
\hline \multicolumn{5}{|l|}{ Total } \\
\hline $0 \mathrm{~h}$ & $0.29 \pm 0.29$ & $0.26 \pm 0.26$ & $1.24 \pm 0.07^{*}$ & $1.59 \pm 0.05^{* *}$ \\
\hline $8 \mathrm{~h}$ & $8.43 \pm 1.87 \#$ & $26.96 \pm 5.53^{*}$ & $22.92 \pm 2.98 \#$ & $27.36 \pm 2.52 \# \# *$ \\
\hline $24 \mathrm{~h}$ & $9.09 \pm 5.88$ & $57.46 \pm 14.98 \# *$ & $38.92 \pm 6.82 \#$ & $49.98 \pm 7.61 \#$ \\
\hline $48 \mathrm{~h}$ & $11.86 \pm 6.29$ & $72.40 \pm 4.30^{* *}$ & $49.53 \pm 5.19 \# *$ & $50.33 \pm 9.33 \# *$ \\
\hline
\end{tabular}

${ }^{a_{\text {The }}}$ effect of NFC and prebiotic FOS is also included. Results are expressed as mean mM of lactic acid or SCFA of three independent fermentations with fecal samples from three different donors \pm standard error of the mean (SEM). \#p $<0.05$ and \#\#p $<0.01$, significantly different from the $0 \mathrm{~h}$ value within the same treatment. ${ }_{p}<0.05, * * p<0.01$, and $* * * p<0.001$, significantly different from NFC at the same time point. nd, not detected.

and conditions in raw red cardoon, whereas they remained substantially bioaccessible in sous-vide-cooked red cardoon. A similar behavior in (poly)phenol bioaccessibility has been observed in cooked white cardoon, ${ }^{3}$ blanched ${ }^{25,26}$ and sousvide-cooked globe artichoke, ${ }^{4}$ which are rich in phenolic acids, mainly CQAs. However, less degradation of (poly)phenols, particularly phenolic acids, was shown in raw Opuntia cactus cladodes, which is rich in pectins, mucilages, and other dietary fibers. $^{22}$ Then, the hydration of the dietary fiber during boiling may favor the retention of phenolic acids into macromolecules, inducing less degradation by digestive enzymes and conditions. This may also explain the positive effect of sous vide heat treatment on the bioaccessibility of red cardoon (poly)phenols and particularly CQAs.

The in vitro anti-inflammatory activity of red cardoon stalks, in two culinary ways of consumption (raw and sous-videcooked), was assessed at both the small intestine (differentiated Caco-2 cells) and colon (HT-29 cells) level. LPS was used to induce a proinflammatory phenotype in both cell lines and thereby to evaluate the ability of red cardoon to protect against LPS-induced secretion of IL-8, IL-6, IL- $1 \beta$, TNF- $\alpha$, and IL-10. No previous studies that evaluate the in vitro immunomodulatory activity of cardoon stalks, whether undigested, GI-digested, or colonic-fermented have been found.

The bioaccessible fraction of GI-digested raw red cardoon, but surprisingly not the sous-vide-cooked one, exerted in vitro anti-inflammatory capacity in the human enterocyte-like cell line Caco-2 (Figure 1). This inflammatory protection was stronger at the highest concentration tested $(9.68 \mathrm{mg} \mathrm{dm} /$ $\mathrm{mL})$, which significantly $(p<0.05)$ counteracted the LPSinduced secretion of IL-8, IL-6, TNF- $\alpha$, and IL-10. Contrarily, the bioaccessible fraction of digested sous-vide-cooked cardoon showed strong proinflammatory effects at the highest tested concentration $(9.68 \mathrm{mg} \mathrm{dm} / \mathrm{mL})$ in Caco-2 cells in the absence of LPS stimulation (Figure 1). The most abundant (poly)phenol of digested red cardoon samples (5-CQA) was able to inhibit TNF- $\alpha$ - and $\mathrm{H}_{2} \mathrm{O}_{2}$-induced IL- 8 secretions in a dose-dependent manner $(0.5-2 \mathrm{mM})$ in differentiated Caco-2 cells. ${ }^{27}$ However, both anti- and proinflammatory effects have been reported in (poly)phenols, and their biological effects depend on the state of the target cells (e.g., resting vs activated), cell ontogeny and pathological conditions (e.g., normal vs cancer cells or macrophages), and the (poly)phenol concentration, exposure times, and pharmacokinetics. ${ }^{28}$ The higher bioaccessibility of (poly)phenols (and potentially other phytochemicals not identified in the current study) in digested sous-vide-cooked red cardoon might have led to an increased absorption of these compounds in the enterocyte-like cells, ${ }^{29}$ causing a proinflammatory response at high concentrations. This study corroborates that the consumption of higher amounts of (poly)phenols in a diet does not necessarily increase inflammatory protection. ${ }^{28}$ Considering a consumption of $150 \mathrm{~g}$ of cardoon, the tested concentrations (i.e., 2.42 and $9.68 \mathrm{mg}$ cardoon $\mathrm{dm} / \mathrm{mL}$ ) would correspond to around 4.7 and $1.2 \mathrm{~L}$ of fluid in the small intestine, respectively. The 
small intestine receives about $9.3 \mathrm{~L}$ of fluid each day and absorbs around $8.3 \mathrm{~L}$ during the day, ${ }^{30}$ so the tested concentrations were considered physiologically achievable. It would also be interesting to assess whether, in a context of a meal in which other non-phenolic-rich foods are included, lower concentrations of (poly)phenols from digested sous-videcooked cardoon could exert anti-inflammatory activity at the small intestine level. Also, further studies on the intestine inflammatory protection of other potential bioactive compounds different than (poly)phenols present in raw red cardoon would be of interest.

In a colon cell model (HT-29), after colonic fermentation, the high proinflammatory activity of NFC at the baseline $(p<$ 0.05) may be related to the presence of some harmful compounds or metabolites derived from the gut microbiota activity of volunteers, which is in agreement with the highly reported adverse effects of fecal water on intestinal cells (cytotoxicity, mutagenicity, and genotoxicity). ${ }^{31,32}$ Gut microbiota action induced the formation of phenolic catabolites, nine of which were identified and quantified in the bioaccessible fractions of colonic fermented raw and sousvide-cooked red cardoon. In the study reported by Juániz et al., 3-(3-hydroxyphenyl)propionic acid was the most abundant catabolite produced during white cardoon stalks in vitro fermentation, ${ }^{3}$ whereas in the current study that catabolite was the second most abundant one after 3-hydroxyphenylacetic acid. Juániz et al. did not identify 3-hydroxyphenylacetic acid, ${ }^{3}$ which might come from the $\alpha$-oxidation of $3-\left(3^{\prime}-\right.$ hydroxyphenyl)propionic acid by gut microbiota. ${ }^{33}$ According to the proposed catabolic pathway for CQA degradation by Ludwig et al., red cardoon (poly)phenols, followed a major pathway that involved the formation of caffeic acid, followed by dihydrocaffeic acid, 3-(3'-hydroxyphenyl)propionic acid and 3-hydroxyphenylacetic acid as the final compounds identified. ${ }^{33}$ Despite the fact that sous-vide-cooked cardoon had a higher total content of (poly)phenols and catabolites (7-8-fold) than the raw one (Table 2), no response was observed in the secretion of cytokines induced by the NFC or LPS (Figures 2 and 3). The tested concentrations of colonic fermented cardoon samples (23.8 and $95.3 \mu \mathrm{g} \mathrm{dm}$ cardoon/ $\mathrm{mL}$ ) were around 100-fold lower than those of the digested vegetable due to cytotoxicity issues and are equivalent to an intake of 312 and $1250 \mathrm{mg}$ of cardoon, respectively, for a fluid volume of $1 \mathrm{~L}$ in the colon. ${ }^{30}$ These data raise the question of whether higher concentrations of colonic fermented red cardoon (raw and sous-vide-cooked) may have the ability to modulate cytokine secretion in HT-29 cells, as digested cardoon did in differentiated Caco- 2 cells.

To the best of the authors' knowledge, this study also reports for the first time the impact of red cardoon (raw and sous-vide-cooked) on gut microbiota composition and SCFA production. Red cardoon showed a potential prebiotic effect on the human microbiota comparable to the well-established prebiotic FOS used as a reference control. Raw and sous-videcooked cardoon led to a beneficial shift of the microbiota composition by increasing health-promoting bacteria such as Bifidobacterium spp. and Lactobacillus/Enterococcus (Figure 4) as well as stimulating the production of SCFAs (Table 3). Moreover, increases in other bacterial populations such as Bacteroides-Prevotella spp. and E. rectale-C. coccoides were detected (Figure 4). Bacteroides-Prevotella spp. (8.5\%) and E. rectale-C. coccoides $(28 \%)$ are two of the most predominant groups in the human fecal microbiota. ${ }^{34}$ Some species of these groups are related with some pathological conditions (Bacteroides are increased in IBD and some species of Clostridium are pathogenic), ${ }^{9}$ but others may be considered potentially beneficial due to their saccharolytic metabolism that results in the production of SCFAs, which are known to have beneficial effects on the host health. ${ }^{35}$ Hence, the $E$. rectale-C. coccoides group includes many acetate- and/or lactate-converting butyrate producers, ${ }^{36}$ and an increase in the production of butyric acid was observed with raw cardoon, sous-vide-cooked cardoon, and FOS fermentations at 24 and 48 $\mathrm{h}$, although it did not reach statistical significance due to great variability in the butyrate production among volunteers (Table 3). In addition, Bacteroides/Prevotella mainly produce acetic, succinic, and propionic acids, ${ }^{37}$ and a significantly high production of propionic acid with the raw and sous-videcooked red cardoon fermentations was observed at 24 and $48 \mathrm{~h}$ $(p<0.05)$, as compared to the baseline. Acetic acid was the main SCFA produced by both raw and sous-vide-cooked cardoon fermentations. This correlates with the fact that acetic acid is the most abundant SCFA produced, representing around $60-75 \%$ of the total SCFA in feces, as acetate synthesis is a widespread ability in the human gut microbiota. ${ }^{37}$

Overall, slight differences were observed between the raw and the sous-vide-cooked vegetable. For instance, sous-videcooked cardoon as the substrate had a higher bifidogenic effect and longer effect in the stimulation of Bacteroides-Prevotella than raw cardoon. The application of culinary treatments has been shown to impact not only bioactive compounds such as (poly)phenols but also dietary fibers. Culinary treatments on vegetables cause the breakdown of macrostructures and mesostructures and increase the solubility of dietary fibers, making them more digestible. ${ }^{36}$ Thus, the differences between raw and sous-vide-cooked red cardoon on the stimulation of different bacterial populations may be related to their different contents of soluble fibers and (poly)phenols (and potentially other bioactive compounds). There is evidence about the ability of both fibers and (poly)phenols to positively modulate the composition and function of gut microbiota. ${ }^{9,10}$ Specifically, dietary fiber (mainly inulin-type fructans) obtained from artichoke, a vegetable that belongs to the same genus as cardoon, showed a prebiotic effect by stimulating the growth of different strains of Lactobacillus and Bifidobacterium spp. ${ }^{38,39}$ In addition, the coffee sample with high levels of chlorogenic acids [the main type of (poly)phenols in coffee that occurs in cardoon] induced a significant increase of Bifidobacterium spp. growth, and an equivalent quantity of chlorogenic acids alone induced the same effects along with an increase of the $C$. coccoides-E. rectale group. ${ }^{40}$ According to this, the stimulation of Bifidobacterium spp. by red cardoon may be due to the action of both fibers and (poly)phenols.

In summary, the application of a culinary treatment, and the GI digestion and gut microbiota action, following a realistic intake in vitro approach affects the (poly)phenol bioaccessibility and bioactivity of red cardoon stalks in the GI tract. Digested raw red cardoon showed anti-inflammatory activity against LPS-induced secretion of IL- 8 , IL- $1 \beta$, TNF- $\alpha$, and IL10 , while digested sous vide red cardoon with a higher content of (poly)phenols showed proinflammatory effects in enterocyte-like cells. However, colonic fermented raw and sous-videcooked cardoon did not show anti-inflammatory activity in HT-29 cells but both induced a beneficial effect on gut microbiota by stimulating Bifidobacterium spp. (especially sous vide cardoon) and Lactobacillus/Enterococcus spp. growth and 
by increasing the production of acetic acid mainly. Therefore, this study provides insights into mechanisms through which red cardoon stalk consumption might influence digestive health and provides evidence for further investigation in health-induced benefits of Cynara vegetables.

\section{ASSOCIATED CONTENT}

\section{SI Supporting Information}

The Supporting Information is available free of charge at https://pubs.acs.org/doi/10.1021/acs.jafc.1c03014.

MS characteristics of (poly)phenolic compounds identified in this study and cytotoxicity (MTT assay) of raw and sous-vide-cooked red cardoon after GI digestion in differentiated Caco- 2 cells and after 8 and $24 \mathrm{~h}$ of colonic fermentation in HT-29 cells, with and without LPS stimulation (PDF)

\section{AUTHOR INFORMATION}

\section{Corresponding Author}

María-Paz de Peña - Departamento de Ciencias de la Alimentación y Fisiología, Facultad de Farmacia y Nutrición, Universidad de Navarra, 31008 Pamplona, Spain; IdiSNA, Navarra Institute for Health Research, 31008 Pamplona, Spain; 이이.org/0000-0002-9994-4268; Phone: +34 948425600 (806580); Email: mpdepena@unav.es; Fax: +34948 425740

\section{Authors}

Estíbaliz Huarte - Departamento de Ciencias de la Alimentación y Fisiología, Facultad de Farmacia y Nutrición, Universidad de Navarra, 31008 Pamplona, Spain; (1) orcid.org/0000-0002-8492-1805

Gessica Serra - Department of Food and Nutritional Sciences, University of Reading, RG6 6AP Reading, U.K.

Andrea Monteagudo-Mera - Department of Food and Nutritional Sciences, University of Reading, RG6 6AP Reading, U.K.

Jeremy Spencer - Department of Food and Nutritional Sciences, University of Reading, RG6 6AP Reading, U.K.

Concepción Cid - Departamento de Ciencias de la Alimentación y Fisiología, Facultad de Farmacia y Nutrición, Universidad de Navarra, 31008 Pamplona, Spain; IdiSNA, Navarra Institute for Health Research, 31008 Pamplona, Spain; orcid.org/0000-0001-6464-5412

Complete contact information is available at: https://pubs.acs.org/10.1021/acs.jafc.1c03014

\section{Funding}

This research was funded by the Spanish Ministry of Science and Innovation (AGL2014-52636-P) and Plan de Investigación de la Universidad de Navarra (PIUNA 2018-09). E. Huarte thanks Asociación de Amigos de la Universidad de Navarra and Banco Santander and the Government of Navarra for the $\mathrm{PhD}$ and mobility grants received, respectively.

\section{Notes}

The authors declare no competing financial interest.

\section{ABBREVIATIONS}

CQAs, caffeoylquinic acids; diCQAs, dicaffeoylquinic acids; FISH, fluorescence in situ hybridization; FOS, fructooligosaccharide; GC-FID, gas chromatography with flame ionization detection; GI, castrointestinal; HPLC-MS/MS, high-performance liquid chromatography with tandem mass spectrometry; IL, interleukin; SCFAs, short-chain fatty acids systemic chronic inflammation; SCI, systemic chronic inflammation; LOQ limit of quantification; MTT, 3-(4,5dimethythiazol-2-yl)-2,5-diphenyltetrazolium bromide; NFC, negative fermentation control; TNF, tumor necrosis factor

\section{REFERENCES}

(1) Furman, D.; Campisi, J.; Verdin, E.; Carrera-Bastos, P.; Targ, S.; Franceschi, C.; Ferrucci, L.; Gilroy, D. W.; Fasano, A.; Miller, G. W.; Miller, A. H.; Mantovani, A.; Weyand, C. M.; Barzilai, N.; Goronzy, J. J.; Rando, T. A.; Effros, R. B.; Lucia, A.; Kleinstreuer, N.; Slavich, G. M. Chronic Inflammation in the Etiology of Disease across the Life Span. Nat. Med. 2019, 25, 1822-1832.

(2) Lahoz, I.; Fernández, J. A.; Migliaro, D.; Macua, J. I.; EgeaGilabert, C. Using Molecular Markers, Nutritional Traits and Field Performance Data to Characterize Cultivated Cardoon Germplasm Resources. Sci. Hortic. 2011, 127, 188-197.

(3) Juániz, I.; Ludwig, I. A.; Bresciani, L.; Dall'Asta, M.; Mena, P.; Del Rio, D.; Cid, C.; de Peña, M.-P. Bioaccessibility of (Poly)Phenolic Compounds of Raw and Cooked Cardoon (Cynara Cardunculus L.) after Simulated Gastrointestinal Digestion and Fermentation by Human Colonic Microbiota. J. Funct. Foods 2017, 32, 195-207.

(4) Domínguez-Fernández, M.; Ludwig, I. A.; De Peña, M.-P.; Cid, C. Bioaccessibility of Tudela Artichoke (Cynara Scolymus Cv. Blanca de Tudela) (Poly)Phenols: The Effects of Heat Treatment, Simulated Gastrointestinal Digestion and Human Colonic Microbiota. Food Funct. 2021, 12, 1996-2011.

(5) Hervert-Hernández, D.; Goñi, I. Dietary Polyphenols and Human Gut Microbiota: A Review. Food Rev. Int. 2011, 27, 154-169.

(6) Yahfoufi, N.; Alsadi, N.; Jambi, M.; Matar, C. The Immunomodulatory and Anti-Inflammatory Role of Polyphenols. Nutrients 2018, 10, 1618.

(7) Zhu, F.; Du, B.; Xu, B. Anti-Inflammatory Effects of Phytochemicals from Fruits, Vegetables, and Food Legumes: A Review. Crit. Rev. Food Sci. Nutr. 2018, 58, 1260-1270.

(8) Majidinia, M.; Bishayee, A.; Yousefi, B. Polyphenols: Major Regulators of Key Components of DNA Damage Response in Cancer. DNA Repair 2019, 82, 102679.

(9) Singh, R. K.; Chang, H.-W.; Yan, D.; Lee, K. M.; Ucmak, D.; Wong, K.; Abrouk, M.; Farahnik, B.; Nakamura, M.; Zhu, T. H.; Bhutani, T.; Liao, W. Influence of Diet on the Gut Microbiome and Implications for Human Health. J. Transl. Med. 2017, 15, 73.

(10) Kumar Singh, A.; Cabral, C.; Kumar, R.; Ganguly, R.; Kumar Rana, H.; Gupta, A.; Rosaria Lauro, M.; Carbone, C.; Reis, F.; Pandey, A. K. Beneficial Effects of Dietary Polyphenols on Gut Microbiota and Strategies to Improve Delivery Efficiency. Nutrients 2019, 11, 2216

(11) Mills, D. J. S.; Tuohy, K. M.; Booth, J.; Buck, M.; Crabbe, M. J. C.; Gibson, G. R.; Ames, J. M. Dietary Glycated Protein Modulates the Colonic Microbiota towards a More Detrimental Composition in Ulcerative Colitis Patients and Non-Ulcerative Colitis Subjects. J. Appl. Microbiol. 2008, 105, 706-714.

(12) Sánchez-Salcedo, E. M.; Mena, P.; García-Viguera, C.; Martínez, J. J.; Hernández, F. Phytochemical Evaluation of White (Morus Alba L.) and Black (Morus Nigra L.) Mulberry Fruits, a Starting Point for the Assessment of Their Beneficial Properties. J. Funct. Foods 2015, 12, 399-408.

(13) Langendijk, P. S.; Schut, F.; Jansen, G. J.; Raangs, G. C.; Kamphuis, G. R.; Wilkinson, M. H.; Welling, G. W. Quantitative Fluorescence in Situ Hybridization of Bifidobacterium Spp. with Genus-Specific 16S RRNA-Targeted Probes and Its Application in Fecal Samples. Appl. Environ. Microbiol. 1995, 61, 3069-3075.

(14) Harmsen, H. J. M.; Elfferi, P.; Schut, F.; Welling, G. W. A 16S RRNA-Targeted Probe for Detection of Lactobacilli and Enterococci in Faecal Samples by Fluorescent In Situ Hybridization. Microb. Ecol. Health Dis. 1999, 11, 3-12. 
(15) Franks, A. H.; Harmsen, H. J. M.; Raangs, G. C.; Jansen, G. J.; Schut, F.; Welling, G. W. Variations of Bacterial Populations in Human Feces Measured by Fluorescent In Situ Hybridization with Group-Specific 16S RRNA-Targeted Oligonucleotide Probes. Appl. Environ. Microbiol. 1998, 64, 3336-3345.

(16) Manz, W.; Amann, R.; Ludwig, W.; Vancanneyt, M.; Schleifer, K.-H. Application of a Suite of 16S RRNA-Specific Oligonucleotide Probes Designed to Investigate Bacteria of the Phylum CytophagaFlavobacter-Bacteroides in the Natural Environment. Microbiology 1996, 142, 1097-1106.

(17) Daims, H.; Brühl, A.; Amann, R.; Schleifer, K.-H.; Wagner, M. The Domain-Specific Probe EUB338 Is Insufficient for the Detection of All Bacteria: Development and Evaluation of a More Comprehensive Probe Set. Syst. Appl. Microbiol. 1999, 22, 434-444.

(18) Daims, H.; Stoecker, K.; Wagner, M. Fluorescence in Situ Hybridization for the Detection of Prokaryotes. In Molecular Microbial Ecology; Osborn, M., Smith, C., Eds.; Taylor \& Francis: Abingdon, U.K., 2005; pp 213-239.

(19) Richardson, A. J.; Calder, A. G.; Stewart, C. S.; Smith, A. Simultaneous Determination of Volatile and Non-volatile Acidic Fermentation Products of Anaerobes by Capillary Gas Chromatography. Lett. Appl. Microbiol. 1989, 9, 5-8.

(20) Palermo, M.; Pellegrini, N.; Fogliano, V. The Effect of Cooking on the Phytochemical Content of Vegetables. J. Sci. Food Agric. 2014, 94, 1057-1070.

(21) Yeo, J.; Shahidi, F. Effect of Hydrothermal Processing on Changes of Insoluble-Bound Phenolics of Lentils. J. Funct. Foods 2017, 38, 716-722.

(22) De Santiago, E.; Pereira-Caro, G.; Moreno-Rojas, J. M.; Cid, C.; De Peña, M.-P. Digestibility of (Poly)Phenols and Antioxidant Activity in Raw and Cooked Cactus Cladodes ( Opuntia FicusIndica). J. Agric. Food Chem. 2018, 66, 5832-5844.

(23) Monente, C.; Ludwig, I. A.; Irigoyen, A.; De Peña, M.-P.; Cid, C. Assessment of Total (Free and Bound) Phenolic Compounds in Spent Coffee Extracts. J. Agric. Food Chem. 2015, 63, 4327-4334.

(24) Nunes, F. M.; Coimbra, M. A. Role of Hydroxycinnamates in Coffee Melanoidin Formation. Phytochem. Rev. 2010, 9, 171-185.

(25) D'Antuono, I.; Garbetta, A.; Linsalata, V.; Minervini, F.; Cardinali, A. Polyphenols from Artichoke Heads (Cynara Cardunculus (L.) Subsp. Scolymus Hayek): In Vitro Bio-Accessibility, Intestinal Uptake and Bioavailability. Food Funct. 2015, 6, 1268-1277.

(26) Garbetta, A.; Capotorto, I.; Cardinali, A.; D’Antuono, I.; Linsalata, V.; Pizzi, F.; Minervini, F. Antioxidant Activity Induced by Main Polyphenols Present in Edible Artichoke Heads: Influence of in Vitro Gastro-Intestinal Digestion. J. Funct. Foods 2014, 10, 456-464.

(27) Shin, H. S.; Satsu, H.; Bae, M.-J.; Zhao, Z.; Ogiwara, H.; Totsuka, M.; Shimizu, M. Anti-Inflammatory Effect of Chlorogenic Acid on the IL-8 Production in Caco-2 Cells and the Dextran Sulphate Sodium-Induced Colitis Symptoms in C57BL/6 Mice. Food Chem. 2015, 168, 167-175.

(28) Focaccetti, C.; Izzi, V.; Benvenuto, M.; Fazi, S.; Ciuffa, S.; Giganti, M. G.; Potenza, V.; Manzari, V.; Modesti, A.; Bei, R. Polyphenols as Immunomodulatory Compounds in the Tumor Microenvironment: Friends or Foes? Int. J. Mol. Sci. 2019, 20, 1714.

(29) de Oliveira, C. L.; Brychkova, G.; Esteves-Ferreira, A. A.; McKeown, P.; de Souza Gomes, M.; Maluf, W. R.; Gomes, L. A. A.; Spillane, C. Thermal Disruption of the Food Matrix of Biofortified Lettuce Varieties Modifies Absorption of Carotenoids by Caco-2 Cells. Food Chem. 2020, 308, 125443.

(30) Tortora, G. J.; Derrickson, B. The Digestive System. In Principles of Anatomy and Physiology, 15th ed.; Wiley, 2016; pp 898950.

(31) Pearson, J. R.; Gill, C. I.; Rowland, I. R. Diet, Fecal Water, and Colon Cancer - Development of a Biomarker. Nutr. Rev. 2009, 67, 509-526.

(32) Gratz, S. W.; Wallace, R. J.; El-Nezami, H. S. Recent Perspectives on the Relations between Fecal Mutagenicity, Genotoxicity, and Diet. Front. Pharmacol. 2011, 2, 4.
(33) Ludwig, I. A.; Paz de Peña, M.; Concepción, C.; Alan, C. Catabolism of Coffee Chlorogenic Acids by Human Colonic Microbiota. BioFactors 2013, 39, 623-632.

(34) Lay, C.; Rigottier-Gois, L.; Holmstrøm, K.; Rajilic, M.; Vaughan, E. E.; de Vos, W. M.; Collins, M. D.; Thiel, R.; Namsolleck, P.; Blaut, M.; Doré, J. Colonic Microbiota Signatures across Five Northern European Countries. Appl. Environ. Microbiol. 2005, 71, 4153-4155.

(35) Tan, J.; McKenzie, C.; Potamitis, M.; Thorburn, A. N.; Mackay, C. R.; Macia, L. The Role of Short-Chain Fatty Acids in Health and Disease. In Advances in Immunology; Elsevier Inc., 2014; Vol. 121, pp 91-119.

(36) Payling, L.; Fraser, K.; Loveday, S. M.; Sims, I.; Roy, N.; McNabb, W. The Effects of Carbohydrate Structure on the Composition and Functionality of the Human Gut Microbiota. Trends Food Sci. Technol. 2020, 97, 233-248.

(37) Louis, P.; Scott, K. P.; Duncan, S. H.; Flint, H. J. Understanding the Effects of Diet on Bacterial Metabolism in the Large Intestine. J. Appl. Microbiol. 2007, 102, 1197-1208.

(38) Zeaiter, Z.; Regonesi, M. E.; Cavini, S.; Labra, M.; Sello, G.; Di Gennaro, P. Extraction and Characterization of Inulin-Type Fructans from Artichoke Wastes and Their Effect on the Growth of Intestinal Bacteria Associated with Health. BioMed Res. Int. 2019, 2019, 1-8.

(39) Fissore, E. N.; Santo Domingo, C.; Gerschenson, L. N.; Giannuzzi, L. A Study of the Effect of Dietary Fiber Fractions Obtained from Artichoke (Cynara Cardunculus L. Var. Scolymus) on the Growth of Intestinal Bacteria Associated with Health. Food Funct. 2015, 6, 1667-1674.

(40) Mills, C. E.; Tzounis, X.; Oruna-Concha, M.-J.; Mottram, D. S.; Gibson, G. R.; Spencer, J. P. E. In Vitro Colonic Metabolism of Coffee and Chlorogenic Acid Results in Selective Changes in Human Faecal Microbiota Growth. Br. J. Nutr. 2015, 113, 1220-1227. 